\title{
Conceptualizing agency: Folkpsychological and folkcommunicative perspectives on plants
}

\author{
bethany 1. ojalehto, ${ }^{a}$ Douglas L. Medin, a and Salino García G. ${ }^{b}$
}

\begin{abstract}
The present research addresses cultural variation in concepts of agency. Across two experiments, we investigate how Indigenous Ngöbe of Panama and US college students interpret and make inferences about nonhuman agency, focusing on plants as a critical test case. In Experiment 1, participants predicted goal-directed actions for plants and other nonhuman kinds and judged their capacities for intentional agency. Goal-directed action is pervasive among living kinds and as such we expected cultural agreement on these predictions. However, we expected that interpretation of the capacities involved would differ based on cultural folktheories. As expected, Ngöbe and US participants both inferred that plants would engage in goal-directed action but Ngöbe were more likely to attribute intentional agency capacities to plants. Experiment 2 extends these findings by investigating action predictions and capacity attributions linked to complex forms of plant social agency recently discovered in botanical sciences (communication, kin altruism). We hypothesized that the Ngöbe view of plants as active agents would productively guide inferences for plant social interaction. Indeed, Ngöbe were more likely than US participants to infer that plants can engage in social behaviors and they also attributed more social agency capacities to plants. We consolidate these findings by using bottom-up
\end{abstract}



of agency rather than variations on a single (universal) model. We consider these findings in light of current theories of domain-specificity and animism, and offer an alternative account based on a folktheory of communication that infers agency on the basis of relational interactions rather

29 than having a mind.

30

31 Keywords: agency concepts; culture; folkpsychology; folkcommunication; Indigenous 


\section{Introduction}

A long-standing question in psychology concerns how people recognize and reason about agents - the kinds of things that are capable of acting in, about, and towards the world. It is widely proposed that this rests on a dualistic distinction between psychological agents versus insentient actors (Johnson, 2003; Wellman \& Johnson, 2008). Specifically, the actions of psychological agents like humans or other animals are explained in terms of mental states like beliefs and desires - a conceptual framework known as folkpsychology (e.g, Erickson et al., 2010). By contrast, the actions of other kinds of actors like plants or clouds are explained by appeal to non-intentional biological (folkbiology) or physical forces (folkphysics). For instance, people purportedly activate different folktheories to interpret what causes movement toward the sun by a cloud versus a plant (folkphysics versus folkbiology), and both would be interpreted differently from what causes a person to move toward the sun (folkpsychology) (Gutheil et al., 1998; Opfer \& Gelman, 2001; Opfer \& Siegler, 2004). This partitioning of domains presents a worldview in which entities in the natural world can be adequately described in terms of physical and biological causes without recourse to intentionality or sociality - properties that are considered exclusive to humans and perhaps some other animals. The corresponding theory of folkpsychology represents an anthropocentric model that may extend agency to some "higher" animals such as mammals, but excludes entities such as plants, minerals, or water bodies on the grounds that they do not share similar forms of agency to humans (e.g., Carey, 1985).

This is the account proposed by domain-specificity theory, which sees these intuitive folktheories as fundamental, untutored ways of organizing knowledge about the world that reflect universal cognitive structure (Hirschfeld \& Gelman, 1994; Sperber \& Hirschfeld, 2004; Wellman \& Gelman, 1992). However, this particular delineation of intuitive domains has been formulated by Western psychologists and much of the evidence in support of it has come from 
Western study populations (Carey, 2009; Gutheil, et al., 1998; Keil, 1995; Opfer, 2002; Opfer \&

57 Gelman, 2001), and some industrialized Eastern cultures (Hatano \& Inagaki, 1994; Inagaki \& Hatano, 2004). Yet more recent research suggests that this organization of domains may reflect patterns of folkbiological reasoning that differ markedly from those of Indigenous communities that take an ecological stance (Herrmann et al., 2010; Ross et al., 2003; Unsworth et al., 2012; Waxman \& Medin, 2007). Based on such findings, it has been proposed that alternative partitionings of domains may provide a better match for conceptual patterns in different cultures-for example, folkecology may be more apt than folkbiology in some Indigenous communities (ojalehto \& Medin, 2015). Similarly, it is a distinct but untested possibility that the anthropocentric stance in folkpsychology may likewise reflect a Western orientation that is not shared in other cultures. In the current research, we propose that folkcommunication may be more apt than folkpsychology in the Indigenous Ngöbe community of Panama. The present experiments investigate whether Indigenous Ngöbe adults and US college students hold different conceptual frameworks for agency that facilitate distinct sets of inferences about and interpretations of nonhuman agency, focusing on plants as a critical test case. ${ }^{1}$

\section{2. Background}

\subsection{Indigenous perspectives on agency}

75 knowledge about agents in ways that differ from Western folkpsychology (Lillard, 1998;

76 Luhrmann, 2011). First, understanding of others is framed more in terms of relational interaction

77 or communication than individual subjectivity (Ingold, 2010). Here the focus is on explaining

\footnotetext{
${ }^{1}$ On Western folkpsychology, capacities like "want" and "think" are interpreted as mental states associated with minds, but it may be that Ngöbe interpret these capacities differently. Thus, we refer broadly to "agency" rather than "minds" or "mental states" in order to avoid specific folkpsychological connotations.
} 
actions in terms of overt behavior, relationships and social roles, and speech acts or other signs rather than explicit inferences about the private mental states of others (Danziger, 2006, 2010; Danziger \& Rumsey, 2013; Duranti, 1988, 2008; Robbins \& Rumsey, 2008). Second,

81 communication with nonhumans is a significant concern in communities where everyday life involves intimate interaction with ecologies (Harvey, 2005; Ingold, 2006, 2011; Kohn, 2013). Personally navigating relationships with nonhuman kinds such as soil, thunder, plants, or animals requires close attention to nonhuman behaviors and responses (Anderson, 1996, 2012; Hallowell, 1960; Rappaport, 1979; Reichel-Dolmatoff, 1976). Native and non-native scholars alike have argued that these exchanges are founded on a conception of nonhumans as beings with a perspective or locus of agency, where agency is understood to be expressed through the capacity to participate in relationships (e.g., predator-prey relations, healing relations) (Bird-David, 1999; Cajete, 2000; Descola, 1996; Kimmerer, 2013; Lima, 1999; Pierotti, 2011; Santos-Granero, 2009; Viveiros de Castro, 1998) (see also Ramos, 2012).²

As a consequence of these views on agency, nonhumans are often included in social relationships within Indigenous communities. For instance, dogs are administered medicinal treatments to enhance their perceptual acuity while hunting, and their behaviors, from barking (while awake or dreaming) to body language and eye contact, are analyzed as meaningful forms of communication (e.g., Kohn, 2007). Plants and animals are also included in the moral circle, as exemplified by such customs as prohibiting rude actions (e.g., spitting) toward plants (Santos-Granero, 2012) and chastising children for wanton harm to insects (Anderson, 2005).

2 These observations have been theorized under distinct frameworks, including animism, perspectivism, and relational epistemology. There are significant differences among these approaches and among Indigenous communities (e.g., Ramos, 2012). However, while anthropological theories of human-nonhuman interaction are debated, the significance of such interactions in everyday life among Indigenous communities is not (Ramos, 2012, p. 483). 
In sum, many Indigenous communities emphasize attention to nonhuman agency and communication - two principles that anthropologists have argued diverge from the Western focus on humans and psychology. To be sure, there is great diversity among Indigenous communities (Descola, 1996). Yet within this diversity, a common principle of many Indigenous epistemologies is that animals, plants, and other natural forces are agents capable of relating and communicating with others and their environments (Pierotti, 2011). In fact, the documented widespread salience of these principles across so many native societies has generated important debates about the nature and extent of cultural variability in this cognitive domain.

\subsection{Understanding cultural variability in agency concepts}

Indigenous ideas about nonhuman agency have figured prominently in theories of cognitive variability across cultures (e.g., Guthrie et al., 1980). Several influential accounts have treated the attribution of agency to nonhuman kinds such as plants as a mistaken inference. Building on the assumption that Western folkpsychology is a universal framework that applies to the proper domain of animates (i.e., humans and animals), these accounts argue that attributing agency to plants represents a "category error" by extending mentalistic attributions beyond the proper intuitive domain (Atran \& Norenzayan, 2004; Boyer, 1996). Such "overextensions" imply a conceptual slippage that requires explanation, and scholars have argued that they represent counterintuitive concepts, religious beliefs, or a strategy adopted in the absence of knowledge (e.g., mistakenly assuming that plants have minds) (e.g., Barrett, 2000; Boyer, 2003; for similar arguments in the developmental domain, see also Kelemen, 2003). In short, overextension accounts assume that the Western folkpsychological concept of mind is universal and cultures vary in how far they extend the concept to nonhumans, resulting in incorrect inferences.

An alternative approach would be to remain neutral about the epistemological status of agency attributions to nonhumans and instead ask on what conceptual grounds such a 
122 framework could support useful inferences. Such inferences would presumably be based on a

123 folktheory that provides a framework for understanding complex behaviors of diverse

124

125

126

127

128 nonhuman kinds, unlike folkpsychology which (by definition) is not applicable to plants and

other non-animals. One possible alternative could take the form of a folktheory of

communication where the relevant explanatory constructs revolve around relationships and

interactions rather than mental states. By focusing on mental states, Westerners take an

anthropocentric stance on the psychological causes of action, presumably using knowledge about

the kinds of entities that have a brain or nervous system as a fundamental constraint on

folkpsychology. Ngöbe do not share this constraint, which frees them to recognize plant behavior

as an instance of agency. A folktheory that uses communicative principles as the basis for

inferring agency would not share this constraint, providing a framework for viewing both plants and animals (as well as other kinds) as agents actively relating to their environments. By

hypothesis, this approach would also encourage a broader stance for observing and expecting complex plant behaviors, specifically forms of interacting and relating. From a

folkcommunication perspective, recognition of nonhuman agency need not index a misguided attribution of mind, but could instead represent an empirically grounded observation of agency as it is expressed through relationships.

The ethnographic record suggests that such a folktheory of communication is evident in various Indigenous communities (e.g., Harvey, 2005; Kohn, 2013), and we have found evidence for this among Ngöbe individuals (ojalehto, Medin, \& Garcia, 2015). When explaining why they attribute agency to plants and other natural abiotic kinds (e.g., sun, ocean), Ngöbe tend to construe agency as a relational property by referring to observable interactions (e.g., growing toward sunlight) and relationships (e.g., producing seedlings). By contrast, we found that US participants tend to construe agency as a psychological property characterized by unobservable 
mental states underlying actions. These findings suggest that Ngöbe and US individuals use different conceptual frameworks for interpreting the actions of agents, and the Ngöbe framework might be better characterized in terms of folkcommunication than folkpsychology.

The above study, like prior ethnographic and psychological studies of animism, relied on verbal reports and predicate attributions (e.g., "Can x think?"). Assessing whether Ngöbe frameworks could lead to productive inferences requires measures of predictive reasoning. To do so we draw on methods by Opfer \& Gelman (2001). They tested the development of folkpsychology and folkbiology by asking US children and adults (1) to predict whether different nonhuman kinds (animals, plants, machines, artifacts) could engage in goal-directed actions, and then (2) to judge the psychological capacities of each kind. This design leverages converging measures to highlight the interaction between inferential reasoning (e.g., predicting that a plant will engage in communicative behavior) and interpretive frameworks (i.e., saying that a plant can communicate). Both forms of evidence are critical for assessing the conceptual commitments underlying nonhuman agency attributions.

\section{Current research}

The present research investigates whether Ngöbe adults and US college students hold distinct folktheories of agency that invoke different interpretations of and guide distinct inferences about nonhuman agents, specifically plants. Plants are a good test case for several reasons. First, plants exhibit the hallmark action patterns that cue agency perception beginning in infancy (Johnson, 2003), including goal-directedness (e.g. phototropism) and contingent interaction (e.g., using chemical defenses when attacked by insects). ${ }^{3}$ Plants are also seen as living kinds on both Western and Indigenous epistemologies, unlike other natural kinds such as

\footnotetext{
${ }^{3}$ One obvious difference between plant and animal action patterns is the slower time scale for sessile plants than motile organisms (in most cases). Apprehending plant agency may require close observation.
} 
the sun or ocean which Ngöbe but not US participants recognize as alive (ojalehto et al., submitted). This provides common ground for recognizing plant movements as cues to autonomous agency, even if Westerners use folkbiology rather than folkpsychology to interpret plant agency (e.g., Opfer \& Gelman, 2001).

Second, the nature and development of conceptual knowledge surrounding plants and plant-human interactions has recently emerged as a topic of inquiry in cognitive psychology (Wertz \& Wynn, 2014a, 2014b). At the same time, biologists are introducing the question of plant intelligence to psychology (Abramson \& Chicas-Mosier, 2016; Cvrčková et al., 2016; Marder, 2012; Trewavas, 2016). Constructs that are central to psychological theories of domain-specific conceptual organization, such as agency or intelligence, are increasingly complicated by the documentation of sophisticated plant behaviors that challenge anthropocentric definitions of those terms.

Finally, plants occupy a contested category in Western science and philosophy (e.g., Hall, 2011). Traditionally, Western scholars have viewed plants as passive objects rather than active agents and favored explanations of plant activity in terms of automatic reactions and mechanistic processes (Hall, 2011; Trewavas, 2002). For instance, Darwin's claim that plant phototropism is an inductive behavior (not a mechanical process) on the part of plants was hotly contested among botanists in the 1800s (see Julius von Weisner (1878) (cf Chamovitz, 2012; Whippo \& Hangarter, 2006). Contemporary debates in plant science center on recent findings that demonstrate complex social capacities of plants, including communication and kin resource sharing (Bhatt et al., 2011; Biedrzycki \& Bais, 2010; Brenner et al., 2006; Dudley \& File, 2007). These findings were unexpected given the prevailing view of plants as having limited capacities. Yet there is now mounting evidence to suggest that basic forms of awareness, memory, and sensory perception are present among plants-indeed, some scientists argue that plant behavior cannot be 
understood without appealing to these capacities (Chamovitz, 2012; Trewavas, 2002, 2003). ${ }^{4}$

Nonetheless, the evidence remains highly debated and some plant scientists flat out reject the possibility of plant sentience (Alpi et al., 2007). It is plausible that these debates are tied to broader cultural conceptions of plants as passive organisms in contrast to sentient animal agents. If so, this would provide indirect evidence to support our hypothesis that interpretative frameworks for agency interact with expectations for actual behavior. On this hypothesis, Ngöbe conceptions of plant capacities may match recent botanical science better than do US college student intuitions. This provides a test bed for observing the role that cultural frameworks play in agency concepts, one that we exploit in the present studies.

The aim of the present research is to explore whether cultural frameworks offer different interpretations for plant capacities and how these frameworks guide predictions for actual plant behavior. Each of our two experiments assessed (a) how people make inferences about behavior (action predictions), and (b) how they interpret that behavior (capacity attributions). These converging measures allow us to test whether conceptual differences go beyond interpretive differences to correlate with distinct inferences about behavioral patterns. We predicted that both groups would predict basic forms of goal-directed action among plants (Exp. 1) but that Ngöbe would be more likely than US participants to predict complex social behaviors among plants (Exp. 2). We also predicted that interpretive frameworks would differ such that Ngöbe would be more likely than US participants to attribute intentional agency capacities (i.e., those associated with goal-directed behavior in Exp. 1) and social agency capacities (i.e., those associated with social behavior in Exp. 2) to plants.

Our proposal implies that agency predicates (e.g., want, communicate) acquire different meanings depending on one's cultural folktheory of agency (folkpsychology or

\footnotetext{
${ }^{4}$ In this regard, it is interesting that some early psychologists argued for a view of psychology that would be broad enough to encompass sessile forms of agency (Heidelberger, 2004; Johnson, 1945; Lindsay, 1876).
} 
215 folkcommunication). A communicative grounding for agency is supported by our prior

216 experiments as well as anthropological reports. But we will also need to consider an alternative

217 interpretation: one might argue that instead of having a different framework for agency, Ngöbe

218 interpret agency predicates in a psychological sense just as Westerners do but differ by extending

219 them to plants. Alternatively, it may also be argued that Ngöbe have greater ecological expertise

220 than US college students, which informs their knowledge about plant behavior independently of

221 underlying agency concepts. We consider both possibilities further in the general discussion.

222 3.1. Language

223 The distinct languages across our cultural samples introduce the possibility of cross-

224 linguistic variation in agency concepts. English is the primary language among US college

225 students. In our Panama research community, most Ngöbe are bilingual in Spanish and Ngöbere,

226 a Chibchan language currently spoken by an estimated 133,000 people in Panama and Costa Rica

227 (Lewis, 2009). A substantial portion of everyday conversation in the community is conducted in

228 Ngöbere, but Spanish is also used frequently and particularly in conversation with non-Ngöbe

229 individuals. With respect to these various languages, one concern is that differences in agency

230 attribution may reflect different semantic mappings for agency terms across English, Spanish,

231 and/or Ngöbere. As an exploratory analysis of potential language effects, we included language

232 as a factor within each cultural group (US: Spanish and English; Panama: Spanish and Ngöbere).

233 Previous research points to both universals and variability in cross-linguistic

234 constructions of agency. Some researchers have argued that universal semantic primitives

235 underlie basic agency terms (e.g., think, feel, want, know, say) across languages, including

236 Spanish and English (Goddard, 2010). This research has focused on agency terms as they apply to

237 human subjects, however, so it is unclear if these semantic primitives also extend (or not) to

238 nonhuman subjects similarly across languages. Furthermore, subtle linguistic differences 
surrounding these putatively universal primitives could still have psychological consequences

240 (Goddard, 2003). Additionally, different grammatical constructions of volitional agency in

241 Spanish versus English have been linked to differential memory for accidental agents (Fausey \&

242 Boroditsky, 2011; Fausey et al., 2010). ${ }^{5}$ These latter findings suggest that language could be a

243 factor in agency attributions.

244 There is no comparable linguistic work on the semantic mapping of agency terms in

245 Ngöbere (P. Young, personal communication, April 25, 2013), but the basic inventory of mental-

246 state terms in Ngöbere has been documented (Kopesec, 1975; Reid, 1994; Sarsaneda del Cid,

247 2009). These terms correspond to those used in the current protocol with adjustment for regional

248 dialect. Notably, Ngöbere has a distinct classifier system for the category of living plants, which

249 is uncommon among world languages and underscores the attention paid to the vegetal world in

250 Ngöbe culture (Young, 1986).

\section{Methods and study populations}

Participants in both two-part experiments were drawn from the same samples of 23

253 Ngöbe adults (7 female) living in an Indigenous community in Panama and 34 US college

254 students (16 female) attending a private Midwestern university, as described below.

\subsection{Panama}

Ngöbe population

The Ngöbe people have resided for millennia in what is now Panama. The primary research community is located on a forested island off the Caribbean coast and numbers around 600 people. Here individuals live in a small-scale community and personally interact with ecosystems through a subsistence relationship with the land and sea, including agroforestry,

${ }^{5}$ To the extent that the effects observed by Fausey et al. might be relevant to the current tasks, they would work against our hypothesis by predicting less agency attribution to actors (and specifically non-volitional actors) among Spanish speakers than English speakers. 
fishing, and diving. Daily life is closely coordinated with the surrounding ecology (Gordon, 1982;

Johannessen, 1970). In terms of formal institutions, the local public school offers primary and public schools. Religious practice includes ecological observances, such as celebrations of lunar events and collective prayers for soil nutrients during periods of poor harvest. Thus, attendance

273 at the Ngöbe Church can be seen as one index of an individual's broader alignment with Ngöbe

274 cultural epistemologies, including ways of knowing, practices, and values.

$275 \quad$ Ngöbe sample

\subsection{United States}


US participants were part of a subject pool associated with an introductory psychology

class at Northwestern University. Students came from predominantly upper-middle class

US sample reported no religiosity $(n=9) .{ }^{6} \mathrm{US}$ participants also reported their childhood places of residency, either in an urban setting (a city or town) $(n=11)$ or a non-urban setting (a suburb, small town, or countryside) $(n=17)$. Participants completed informed consent and received partial course credit

294 for participating.

\subsection{Procedure}

In Panama, participants were interviewed in Ngöbere or Spanish by two authors (S.G.G. and b.l.o.). In the US, participants completed a computer-based survey in English or Spanish.

298 These were selected as the most culturally appropriate methods for each context, reflecting 299 typical methods used in small-scale communities and university settings, respectively. The Spanish protocols were independently forward- and back-translated between

301 English and Spanish by two trained research assistants in the US; before use in Panama, protocols 302 were reviewed for local accuracy by S.G.G. Ngöbere protocol translation was also conducted by 303 S.G.G., who has linguistic expertise in Ngöbere. A second community member trained in 304 research methods reviewed and back-translated critical phrases of the Ngöbere protocol. During 305 Ngöbere interviews in Panama, S.G.G. translated the participant's responses immediately into

\footnotetext{
${ }^{6}$ Demographic data were available from 28 of the 34 US participants.
} 
306 Spanish. Interview responses were audio-recorded and later transcribed and translated from

307 Spanish into English by a trained bilingual research assistant in the US.

\section{Experiment 1A: Goal-directed action predictions}

Acting toward self-beneficial goals represents a basic survival behavior that is a

310 pervasive, readily observable characteristic of living kinds (Opfer, 2002; Opfer \& Gelman, 2001).

311 As such, plant goal-directed behavior should be recognized by both US and Ngöbe informants

312 even if, as we hypothesize in Experiment 1B, it will be interpreted under different frameworks.

313 Therefore, we predicted cultural agreement on action predictions for plant goal-directed agency

314 in Experiment 1A.

315 5.1. Participants

316 Participants were 23 Ngöbe (7 females) and 33 US participants (16 females). One

317 additional US participant was excluded due to experimenter error. Gender was not found to have

318 an effect on the primary findings for any experiments. Where gender effects were found for

319 secondary analyses, those are reported in footnotes.

\subsection{Materials and methods}

Stimuli were colored line drawings of plants, animals, machines, and simple artifacts

322 (three of each kind) from Opfer and Gelman (2001) (see original study for materials). Participants

323 predicted whether each entity would change its current direction of movement in response to the

324 presence of an object, representing either a self-beneficial goal object such as food or sunlight

325 (Benefit Present condition, BP) or a neutral object, such as a rock or picture (Benefit Absent

326 condition, BA). In the BP condition, predicting that the entity would change its direction of

327 movement towards the beneficial object was coded as a goal-directed action prediction (scored as

328 1). Otherwise, predicting that the entity would not change its direction of movement (toward a 
neutral object in the BA condition, or at all in the BP condition) was coded as no goal-directed action (scored as 0). Following the original study, the purpose of the BA condition was to provide a control where changes in movement would not be systematically predicted, to strengthen the interpretation that predictions for a change in movement for the BP condition are genuinely goaldirected judgments. Stimuli were randomly presented within randomized (US) or counterbalanced (Panama) kind blocks.

Culturally appropriate adjustments were made to select stimuli in Panama to avoid potential confounds related to item familiarity (see Appendix A1). A few modest changes were made part way through the study. We began our interviews with the original indoor potted plant item $(N=13)$ but then replaced it with an outdoor ground vine (conserving the growth movement pattern and goal of sunlight) for subsequent interviews $(N=10)$. Ngöbe do not grow plants indoors, so the vine represented a more familiar context for reasoning about sunlightdirected growth patterns. Where differences are found for the plant item, analyses are reported in footnotes. We also replaced the original novel machine items with three familiar machines to ensure that Ngöbe informants were not reasoning based on inferred special properties of novel machines. There were no differences in action predictions or agency attributions for novel $(N=$ 10) versus familiar $(N=13)$ machine stimuli.

\subsection{Results}

We predicted cultural agreement on predictions for goal-directed action, such that plants and animals, but not machines and artifacts, will be viewed as capable of acting toward selfbeneficial goals. There should also be an overall agreement that agents will not systematically act toward neutral objects, as this does not represent a case of genuinely goal-directed behavior. Goal-directed action predictions were averaged across the three entities for each kind. Tests were conducted with a 4-factor (kind: animal, plant, machine, other artifact) repeated-measures 
ANOVA on action predictions, with condition (benefit present versus absent; BP, BA) and culture as between-subjects variables. Interactions were investigated with separate analyses for either kind or condition, as appropriate. Follow-up tests were conducted with Bonferroni corrections. As expected, there was broad cultural agreement on action predictions. No reliable cultural differences emerged for any individual item or kind (all $p s>.10)$ (see Table 1). ${ }^{7}$ Both Ngöbe and US participants expected plants and animals to act toward goals more often than machines and simple artifacts, and to do so more when a benefit was present than when it was not. The main effect of kind, $F(3,156)=97.42, p<.01, \eta^{2}=.65$, when broken down by specific contrasts, indicated that participants predicted goal-directed actions for animals more than all other kinds $(M=.85, S D=.27)$, and also predicted more goal-directed action for plants $(M=.61$, $S D=.38)$ than machines $(M=.20, S D=.32)$ or artifacts $(M=.17, S D=.25)$ (all $\left.\mathrm{p}^{\prime} \mathrm{s}<.05\right)$ (machines and simple artifacts did not differ). ${ }^{8}$ Additionally, participants were more likely to predict goaldirected actions in the BP condition $(M=.59, S D=.16)$, than the BA condition $(M=.32, S D=.16)$, $F(1,52)=39.67, p<.01, \eta^{2}=.43$, indicating cross-cultural agreement that self-beneficial (as compared to neutral) objects prompt more goal-directed actions among both plants and animals.

\footnotetext{
${ }^{7}$ Among our Ngöbe sample, differences were found across the two plant stimulus versions (original and culture-specific). Participants were more likely to predict goal-directed action for the culturally familiar ground vine $(M=.80, S D=.42)$ than the original indoor potted plant $(M=.31, S D=.48)$ across both BP and BA conditions, $F(1,19)=5.16, p<.05, \eta^{2}=.21$. However, this effect held for all three plant items although the indoor/outdoor plant was the only item that differed across versions, so the observed difference cannot be due to the familiar versus unfamiliar item. This finding may instead reflect participant demographics, given that participants in the familiar plant stimulus condition also tended to have less schooling (correlated with stimulus version $r=-.62, p<.01)$ and were also more likely to be members of the Ngöbe church $(r=.59, p<$ $.01)$.

${ }^{8}$ Among US participants, females predicted more goal-directed actions for machines $(M=.56, S D=.41)$ than males $(M=.19, S D=.24)$ in the BP condition only, $F(3,87)=2.97, p<.05, \eta^{2}=.09$. This gender difference was unexpected. Action predictions for the other three kinds did not differ.
} 
Table 1: Predictions of goal-directed action by culture, kind, and condition

\begin{tabular}{lllllllll}
\hline \multirow{2}{*}{ Condition / Culture } & \multicolumn{2}{c}{ Animals } & \multicolumn{2}{c}{ Plants } & \multicolumn{2}{c}{ Machines } & \multicolumn{2}{c}{ Artifacts } \\
& Mean & SD & Mean & $S D$ & Mean & SD & Mean & $S D$ \\
\hline Benefit-Present Condition & & & & & & & & \\
$\quad$ Ngöbe & 1 & 0 & 0.82 & 0.35 & 0.18 & 0.40 & 0.33 & 0.30 \\
$\quad$ US & 0.96 & 0.11 & 0.91 & 0.25 & 0.37 & 0.38 & 0.11 & 0.26 \\
$\quad \begin{array}{l}\text { Benefit-Absent Condition } \\
\quad \text { Ngöbe }\end{array}$ & & & & & & & & \\
$\quad$ US & 0.72 & 0.4 & 0.36 & 0.22 & 0.14 & 0.22 & 0.17 & 0.22 \\
\hline
\end{tabular}

5.4. Discussion

We expected and found cross-cultural agreement on predictions concerning the kinds of agents that can act toward self-beneficial goals-namely, plants and animals, but not machines or artifacts. We now turn to the critical question of how such action capacities are interpreted.

\section{Experiment 1B: Capacity attribution}

After completing Experiment 1A, the same participants judged five agency capacities

375 (see, want, feel, think, feel pain) of each entity (following Opfer \& Gelman, 2001). ${ }^{9}$ The key

376 question concerns capacity attributions to plants. We predicted that Ngöbe but not US

377 participants would extend capacity attributions (e.g., thinking, feeling pain) to plants as well as

378 animals. By hypothesis, this difference arises because these predicates correspond to two

379 different sets of meanings (communicative or psychological) on the two cultural frameworks for

380 agency. If agency capacities are conceptualized under a folkcommunicative framework focused

381 on interactions with the environment, then capacity attribution profiles should keep plants closer

382 to animals than to inanimate machines and simple artifacts (Ngöbe). If these capacities are

383 conceptualized under a folkpsychological framework focused on having a mind, then plants

384 should be closer to other inanimates than they are to animates (US).

\footnotetext{
${ }^{9}$ One additional US participant did complete Exp. 1A but was excluded from Exp. 1B due to experimenter error.
} 


\subsection{Materials and methods}

Stimuli were the same as in Experiment 1A (including the culture-specific plant and machine items). Participants were asked if each entity could see, want, feel, think, and feel pain (see Appendix A2). Items were blocked by kind in counterbalanced (Panama) or randomized order (US) and capacity probes were presented in counterbalanced order.

\subsection{Results}

Capacity attributions were averaged across the three entities by kind. To explore cultural differences, attributions were analyzed with a 2 (culture) by 4 (kind) by 5 (capacity) repeatedmeasures ANOVA. Here we report only the focal cultural contrasts; for full results, see Appendix A3.

As shown in Figure 1, the critical interaction of culture by kind was significant, $F(3,162)=$ 13.09, $p<.001, \eta^{2}=.20$. Follow-up comparisons (Bonferroni-corrected) showed that Ngöbe attributed more capacities to plants $(M=.61, S D=.33)$ than did US participants $(M=.26, S D=$ $.20), \mathrm{t}(32.75)=4.62, p<.001, d=1.61$. Cultural patterns of attribution to artifacts also differed, $\mathrm{t}(22.30)=2.32, p<.05, d=0.98$, but not to animals or machines (see Appendix A3).

As is evident from the overall attribution profiles in Figure 1, both groups differentiated among animals, plants, and artifacts (machines and simple objects), but the distinctions drawn between those categories fell at different points. For Ngöbe, plants possess substantial agency capacities and stand closer to animals than to inanimate artifacts. By contrast, US participants denied almost all capacities to plants, placing them closer to inanimate artifacts than animals. On the proposed folkcommunication framework, one prediction is that mappings between action predictions and capacity attributions should be nearly one-to-one because the ability to interact may itself be interpreted as communication. If so, we should find that goaldirected action predictions correlate with agency attributions among Ngöbe participants. This 
409 was in fact the case for all three non-animal kinds: action predictions and capacity attributions

410 were correlated for plants (partial $r=.47, p<.05, \mathrm{df}=20$, controlling for BP/BA condition), artifacts

411 (partial $r=.49, p<.05 . \mathrm{df}=20$ ) and machines (partial $r=.43, p<.05, \mathrm{df}=20$ ). In contrast, US

412 individuals should not evidence this same mapping because action is selectively linked to

413 folkpsychological agency attributions, as action is interpreted differently for different kinds

414 according to domain-specific frameworks (physical, biological, or mental). Consistent with this,

415 there were no reliable correlations between action predictions and agency attributions for any

416 kind among US participants. These observations indicate that the mapping from goal-directed

417 action to agency attribution is more direct for Ngöbe than for US participants, in line with the

418 idea that Ngöbe infer agency on the basis of a capacity to interact.

419 Ngöbe informants also made more capacity attributions across all four kinds than US

420 participants, $F(1,54)=15.26, p<.001, \eta^{2}=.22$, and this trend held reliably for every capacity

421 except thinking, $p s<.05$. The three-way interaction among culture, capacity, and kind, $F(12,648)$

$422=4.59, p<.001, \eta^{2}=.08$, indicated that cultural attributions for each kind varied according to

423 specific capacity. To illuminate these patterns, a 2 (culture) by 5 (capacity) repeated-measures

424 ANOVA was performed on attributions for each kind separately; here we report findings for the

425 key test case of plants (see Appendix A3 for other kinds). 
Figure 1: Capacity attributions by kind and culture

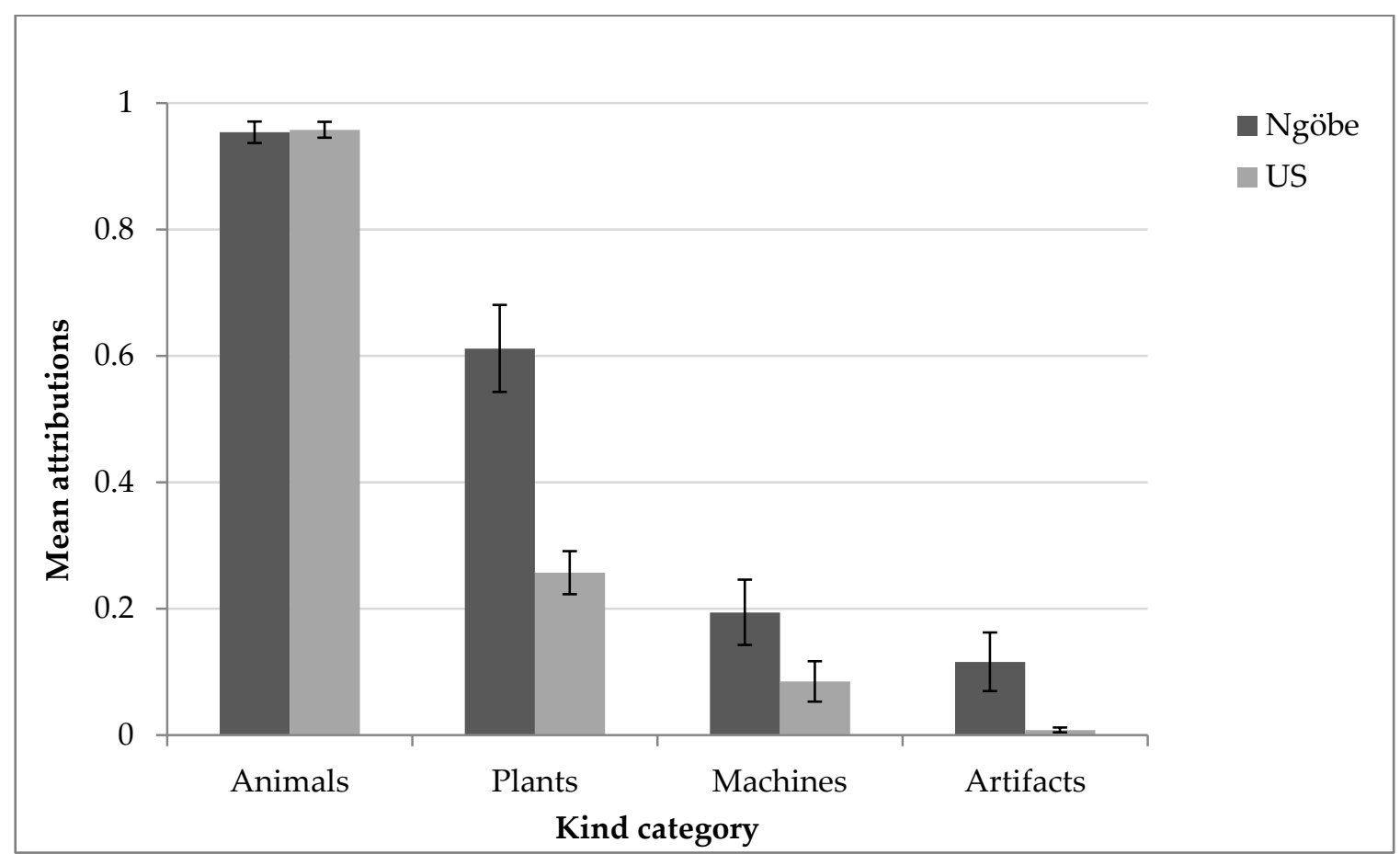

Plants. As indicated in Figure 2, Ngöbe were more likely than US participants to attribute every capacity except thinking to plants. Ngöbe endorsed plant capacities for feeling, wanting, and pain at levels well above chance (2-tailed $p s<.05)$, while thinking was endorsed slightly above chance $(n s)$. In contrast, US attributions dropped off precipitously for every agency capacity except feeling, with wanting endorsed at low levels (ns), and pain and thinking strongly rejected (2-tailed $p s<.01)$. Notably, Ngöbe were over seven times more likely than US participants to say that plants can experience pain. 


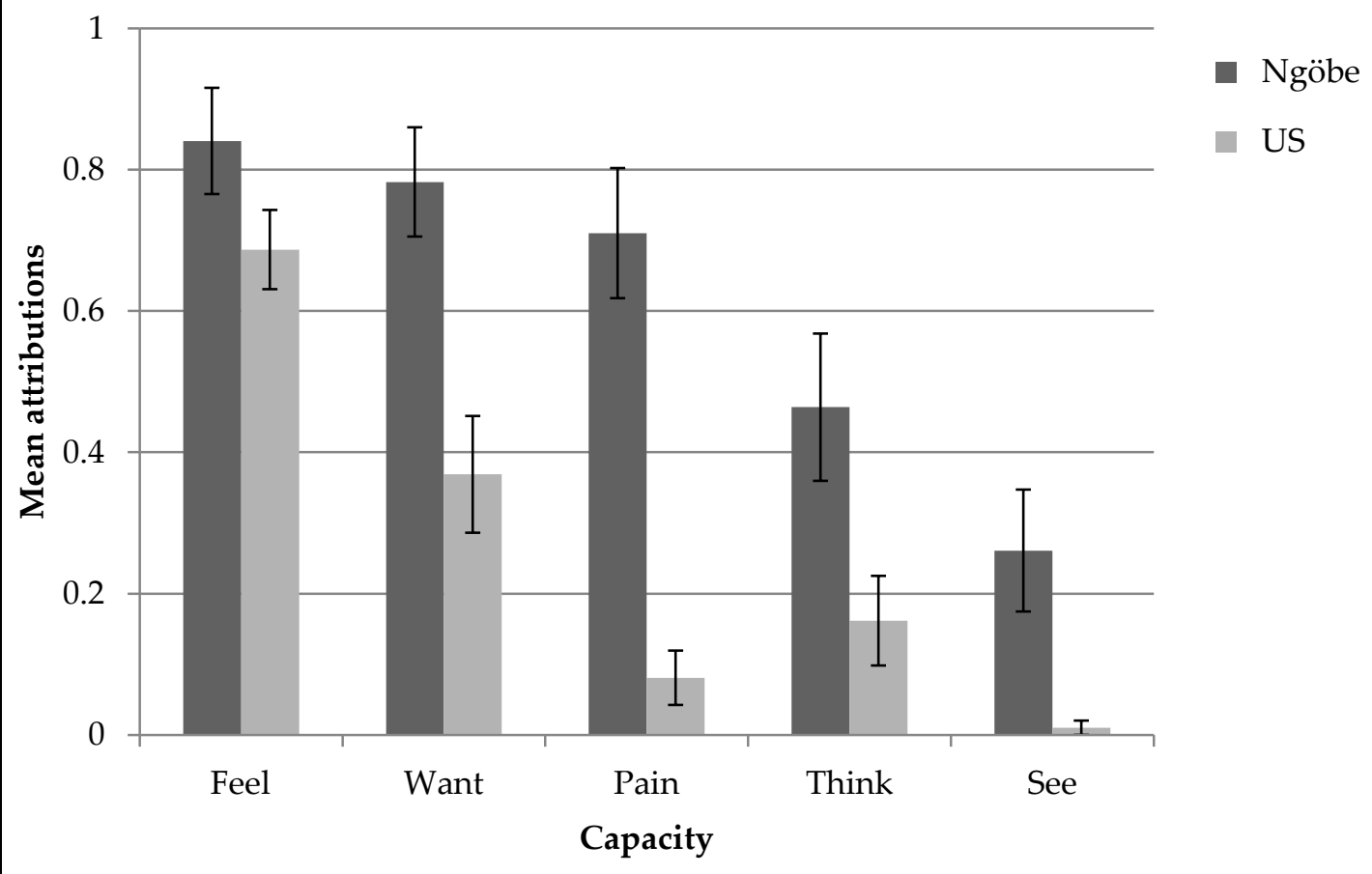

\subsection{Discussion}

In Experiment 1B, our key prediction concerning plant agency was borne out: Ngöbe

were far more likely than US participants to attribute agency capacities to plants. Not only was

this cultural pattern robust across every capacity except thinking (which was still a strong trend),

443 but also the effects were large enough to suggest qualitatively distinct models for plant agency.

444 On the Ngöbe model of agency attribution, plants stand in closer relation to animate agents than

445 they do to inanimate artifacts. In direct contrast, the US model denies most capacities to plants,

446 placing them in closer relation to inanimate objects than to animals.

Interestingly, most participants in both groups agreed that plants can feel, replicating 
tended to agree that plants cannot see, evidently interpreting sight as a visual capacity requiring eyes. Presumably, attributions would have been higher for a more neutral probe such as "detect" or "perceive." It may be that the observable relationship between eyes and sight supports crossculturally shared intuitions about this capacity (see also Meltzoff \& Gopnik, 2013). By contrast, the properties (e.g., mind) underlying folkpsychological construals of capacities such as wanting or pain are less observable, and this may contribute to greater cross-cultural divergence in corresponding intuitions. We speculate that "thinking" may have elicited relatively fewer attributions among Ngöbe because it rarely lends itself to expression through an observable relationship such as wanting (e.g., growing toward sunlight) or pain (e.g., producing sap when cut), so could be less relevant to a communicative folk theory.

A limited number of Ngöbe informants also endorsed certain capacities for artifacts and machines, producing small but reliable cultural effects in agency attributions for those two kinds. Though these attributions may suggest a positive response bias for some Ngöbe participants, the effects were not of sufficient magnitude to account for the focal cultural differences in plant agency attributions.

\subsection{Experiment 1: Overall discussion}

Experiment 1 showed that Ngöbe and US participants both recognize goal-directed action among plants and animals, but the interpretations given to this agency differ across cultures. On the US model, these agency capacities are seen as unique to animals so that plant goal-directed action does not warrant attribution of psychological states. The Ngöbe results, by contrast, indicate that these agency capacities are construed as properties shared to a substantial extent by both plants and animals. By hypothesis, this reflects an alternative interpretive framework: Ngöbe view plant goal-directed action as evidence of a relational capacity for communication. Ngöbe capacity attributions represent a departure from the domain-specific 
view that plants are denied the intentional capacities typically associated with animals. In Experiment 2 we tested the idea that different frameworks for agency will afford distinct inferences and interpretations in a novel domain of plant behavior-social agency.

\section{Experiment 2A: Action predictions for plant social interactions}

Experiment 2 focuses on concepts of plant social agency, specifically plant communication and kin altruism. ${ }^{10}$ These social capacities were selected because they represent a recent area of Western botanical science where the interpretation of findings is still subject to debate. Not surprisingly given the recentness of these discoveries, plant social interactions are subtle and less directly observable than the self-beneficial goal-directed actions from Experiment

1. Presumably then, plant social interactions are not common knowledge among laypersons. This provides a test bed for assessing how people reason about plant behavior on the basis of intuitive conceptual frameworks rather than simple fact retrieval. We hypothesize that Ngöbe should be more likely than US participants to predict that plants will engage in social behaviors, on the basis of an ecocentric folktheory that provides a lens for observing and expecting complex communicative exchanges among organisms and their environments.

As in Experiment 1, illustrated scenarios were used to assess action predictions (Experiment 2A) and corresponding capacity attributions (Experiment 2B) concerning communication and kin altruism. Unlike Experiment 1, however, we now expected action predictions to differ in addition to capacity attributions.

\footnotetext{
${ }^{10}$ We describe these plant interactions as communication, kin recognition, and kin altruism following the scientific botanical literature (e.g., Bhatt, et al., 2011; Biedrzycki \& Bais, 2010; Falik et al., 2011), while recognizing that some readers may prefer leaner terms such as signaling.
} 
515 Simard, 2009; Wilkinson, 1998). In each scenario, participants predicted whether or not the more

\subsection{Participants}

Participants were 17 Ngöbe ( 5 female) and 30 US (13 female) participants from

Experiment 1. Ngöbe samples were smaller than in Experiment 1 because pilot interviews were conducted to refine the protocol (see Appendix C1).

\subsection{Materials and methods}

Participants were presented with four line drawn sequences of plants engaged in events characteristic of communicative signaling and kin-selective resource sharing (see Figure 3; complete materials in Appendix C2). For each scenario, participants were told that the plants were connected via roots and asked to predict whether or not one plant would modify its activity in response to another plant. Thus they always chose between two outcomes: either the plants would interact, leading to an adaptive change for one plant, typically the receiver plant (coded as a social interaction prediction, scored as 1); or there would be no interaction between the plants and therefore no adaptive change for either plant (coded as no social interaction prediction, scored as 0$)$.

The two communication scenarios involved root-connected plants signaling in response to drought or an insect plague, prompting an anticipatory adaptive response in the receiving plant (modeled on experimental results reported in Falik et al., 2011; Heil \& Karban, 2010) (see Figure 3). In each scenario, participants predicted whether or not the receiver plant(s) would already be in a prepared state prior to the arrival of the threatening event. The two kin altruism scenarios involved resource sharing, either between two sibling plants or a mother tree and her seedling (modeled on experimental results and observations reported in Dudley \& File, 2007; mature plant would modify its resource consumption such that the less mature plant would benefit. For all four scenarios, the experimental logic was that action predictions would be made 
on the basis of inferred communication or kin resource sharing, respectively. Analysis of

\section{Figure 3: Illustration of prediction scenario for plant interactions}

Drought scenario

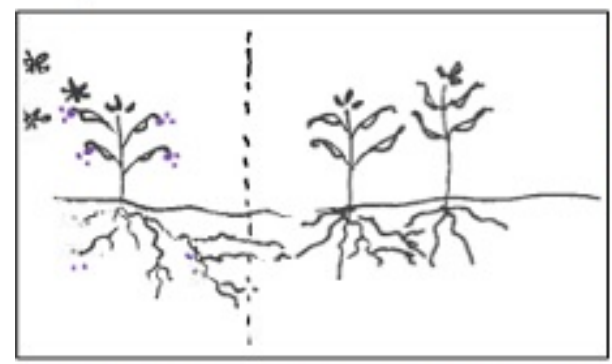

1a. Here are three plants of the same species. Aboveground, a wall separates the left plant from the two on the right, but the roots are connected. Insects have arrived and are irritating the plant on the left. As a result, the plant has released chemicals to defend itself. The chemical is released through both leaves and roots.

1b. What will happen to the two plants cn the other side, after the left plant releases defensive dhemicals? (Assume the insects have not arrived con the right side of the wall yet.)

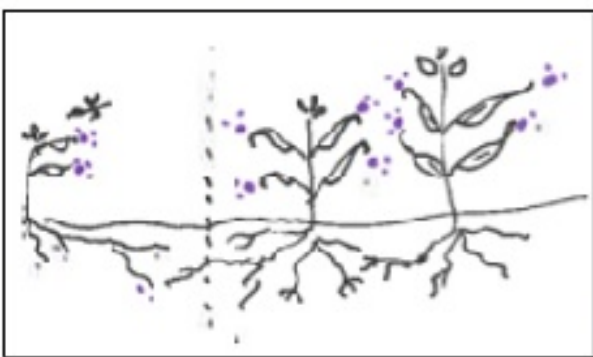

2a. The other two plants will also release chemicals to defend themsel ves.

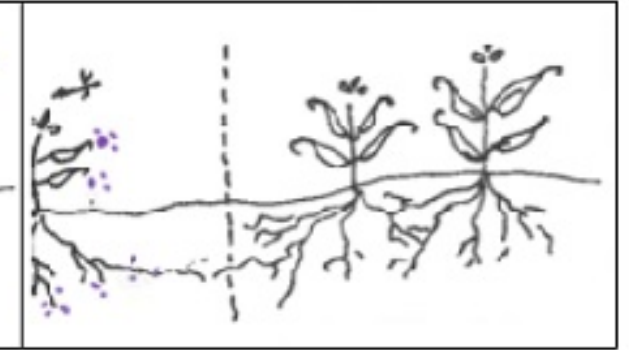

$2 \mathrm{~b}$. The other two plants will remain in the same state as before, with out releasing chemicals.

${ }^{11}$ For the drought communication scenario, some participants explained that the connected plant would survive the drought due to water sharing between plants, thus inferring that the interaction involved resource sharing rather than communication. These responses were analyzed in the same manner as other communication predictions as they are consistent with an overall focus on plant social behavior. 


\subsection{Results}

As indicated in Figure 4, Ngöbe were more likely than US participants to predict that plants would communicate and share resources with kin. The two prediction scenarios in each domain (communication, kin altruism) were conceptually similar and exhibited similar results (see Appendix C3), so a composite measure was created by averaging across those two predictions for each participant. Instances where participants did not offer a prediction ("don't know" or no opinion) were treated as missing data (2 US participants, 1 Ngöbe participant). Communication: Ngöbe were reliably more likely to predict that connected plants would be prepared for the arrival of drought or insects $(M=.91, S D=.26)$ than were US participants ( $M$ $=.70 S D=.31), F(1,45)=5.59, p<.05, \eta^{2}=.11 .{ }^{12}$ Kin altruism: Ngöbe were reliably more likely to predict that plants would share resources with kin $(M=.59, S D=.32)$ than US participants $(M=$ $.32, S D=.40), F(1,45)=5.66, p<.05, \eta^{2}=.11$.

${ }^{12}$ Gender effects were found for kin altruism predictions among US participants, $F(1,28)=4.12, p=.05, \eta^{2}=$ .13 , such that males $(M=.44, S D=.43)$ were more likely than females to predict kin altruism $(M=.15, S D=$ .32). There were no reliable effects of gender among Ngöbe participants. 
Figure 4: Action predictions for plant social interactions by culture

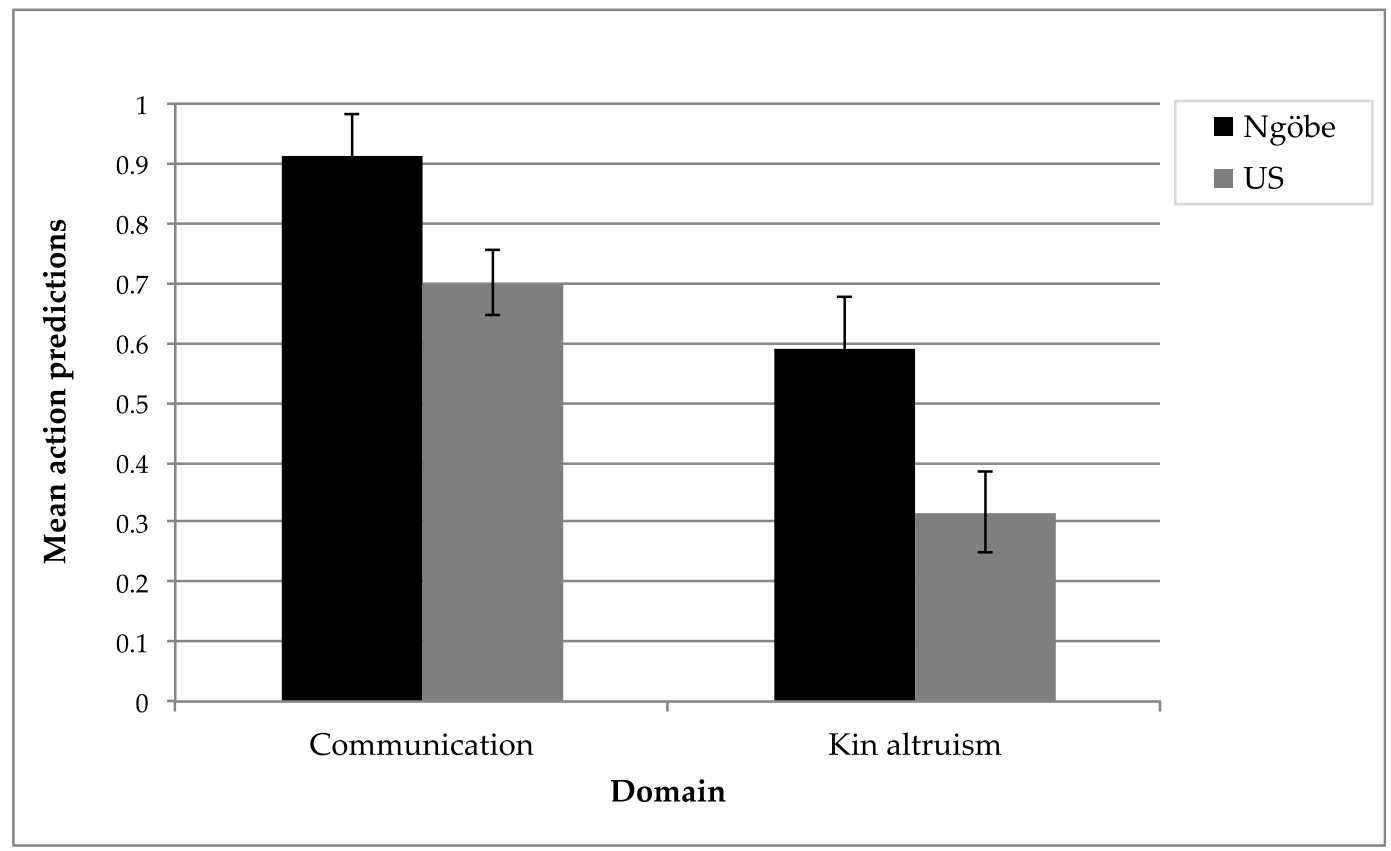

The finding that a majority of both Ngöbe and US participants predicted plant

communication raises the question of how such interactions among plants are interpreted. To explore this hypothesis, we analyzed explanations for positive communication predictions (excluding participants who predicted no communication). We predicted that Ngöbe participants would explain plant communication as a genuinely social interaction involving intentional transactions directed toward other plants, whereas US participants would be more likely to see communication as a byproduct of individual survival goals or reductive biological mechanisms. Each explanation received one of three mutually exclusive codes: (1) social goal, (2) individual goal, or (3) (non-goal-directed) biological and/or physical mechanisms (see coding table in Appendix C4). Explanations that identified a purposive action of one or both individual plant(s) and linked this to a beneficial outcome (e.g., adaptation, survival, growth) were coded as goal-directed. Goal-directed explanations then could fall into one of two categories. An explanation that cited an other-beneficial goal as the cause or purpose of one plant's interaction 
with another plant was coded as a social goal (e.g., signaling for the receiving plant's benefit;

helping or protecting another plant; such as, "They were communicating underground and telling the other tree, they were warning it that it has to save some water."). An explanation that cited self-beneficial goals as the cause of plant interaction was coded as an individual goal. In such cases, the beneficial outcome was facilitated by plant interaction (e.g., root contact), but it was a byproduct rather than the goal of that interaction (e.g., "They sense the chemicals and it's a natural response to survive"). Explanations that did not identify any goal but instead focused on non-purposive causes of action (biological processes, physics, or generic factors) were coded as mechanistic (e.g., innate reactions, automatic processes, or physical mechanisms, as well as species-level evolutionary mechanisms).

As indicated in Table 2, there were reliable cultural differences in interpretations of plant communication for both scenarios (Drought: $\chi^{2}(1, N=36)=9.24$, exact, 2-sided $p<.01$; Insects: $\chi^{2}$ $(1, N=37)=18.60$, exact, 2 -sided $p<.01) \cdot{ }^{13}$ Ngöbe were far more likely to explain plant communication in terms of social goals (20/31) than individual goals $(8 / 31)$ or non-intentional mechanisms (3/31). By contrast, US participants rarely explained plant communication as a social interaction (2/42) and instead favored individual goals (20/42), or non-intentional mechanisms (20/42). US respondents in particular often stressed the non-intentional nature of plant activity, as in, "Some sort of chain reaction thing...no thinking, just reactions."

\footnotetext{
${ }^{13}$ We report the N-1 chi-square test rather than Pearson's chi-square, because the $\mathrm{N}-1$ is more robust to low expected counts and is recommended for small samples (Campbell, 2007). The linear-by-linear association test generated in SPSS CROSSTABS is equivalent to the N-1 chi-square (Weaver, 2013).
} 
Table 2: Interpretations of plant communication for each prediction scenario

\begin{tabular}{|c|c|c|c|c|}
\hline Scenario / Culture & Social goal & $\begin{array}{l}\text { Individual } \\
\text { goal }\end{array}$ & Mechanistic & Total \\
\hline \multicolumn{5}{|c|}{ Drought scenario $(N=36)^{*}$} \\
\hline Ngöbe & $9(60 \%)$ & $3(20 \%)$ & $3(20 \%)$ & 15 \\
\hline US & $1(5 \%)$ & $10(48 \%)$ & $10(48 \%)$ & 21 \\
\hline \multicolumn{5}{|c|}{ Insect scenario $(N=37)^{*}$} \\
\hline Ngöbe & $11(69 \%)$ & $5(31 \%)$ & $0(0 \%)$ & 16 \\
\hline US & $1(5 \%)$ & $10(48 \%)$ & $10(48 \%)$ & 21 \\
\hline
\end{tabular}

${ }^{*} N=$ number of participants who made a positive action prediction for that scenario (excluding explanations given by participants who predicted no action). interpret communication as a byproduct of individual survival goals and biological mechanisms. capacity attributions concerning plant social agency.

\section{Experiment 2B: Capacity attributions for plant social interactions}

communication (signaling) and kin altruism (kin recognition, helping, feeling another plant's

587 pain). We predicted that Ngöbe would be more likely than US participants to attribute these

588 social agency capacities to plants, particularly those associated with kin altruism, in keeping with

589 their greater recognition of complex social behaviors among plants.

\subsection{Participants}




\subsection{Materials and methods}

Participants judged whether plants are capable of four capacities: (1) recognizing kin, (2) helping offspring via roots, (3) signaling or communicating, and (4) feeling pain for another injured plant (see full probes in Appendix C4). Each item was presented immediately after the matching illustrated prediction scenario from Experiment 2A (and in the same order) such that Experiments 2A and 2B were interwoven. The pain item was always presented last, accompanied by a photograph of a fallen tree surrounded by other trees.

\subsection{Results}

Capacity attributions were scored as yes or no, excluding “don't know" responses. The data from one Ngöbe participant who provided 2 such responses were excluded from analysis. Attributions were analyzed with a 2 (culture) by 4 (capacity) repeated-measures ANOVA. Only the focal cultural contrasts are reported here; for full results, see Appendix C5.

As indicated in Figure 5, Ngöbe were more likely than US participants to attribute social agency capacities to plants (Ngöbe $M=.84, S D=.27$; US $M=.38, S D=.27$ ), $F(1,42)=27.39, p<$ $.001, \eta^{2}=.40$. This was reliable for each capacity individually $(\operatorname{Fs}(1,42)=$ from 6.67 to 68.28 , all $p s<$ .05), except plant signaling, where the cultural trend was only marginally significant, $F(1,42)=$ $2.90, p=.10, \eta^{2}=.07$

The interaction of culture by capacity, $F(3,126)=3.47, p<.05, \eta^{2}=.08$, showed that the extent of divergence between US and Ngöbe attributions differed across particular capacities, with individual social capacity attributions varying more among US than Ngöbe participants. US attributions did not extend to feeling another plant's pain, leading to reliable interaction effects, $F(3,87)=16.12, p<.001, \eta^{2}=.36$. In contrast, Ngöbe attributions were uniformly high (all were above chance, $p s<.05$, except kin recognition $p=.07$ ), and there were no reliable differences in attributions across the four capacities, $F(3,39)=.07$, $n s$ (for pairwise comparisons, all $p s>.99$ ). 
Figure 5: Social capacity attributions to plants by culture

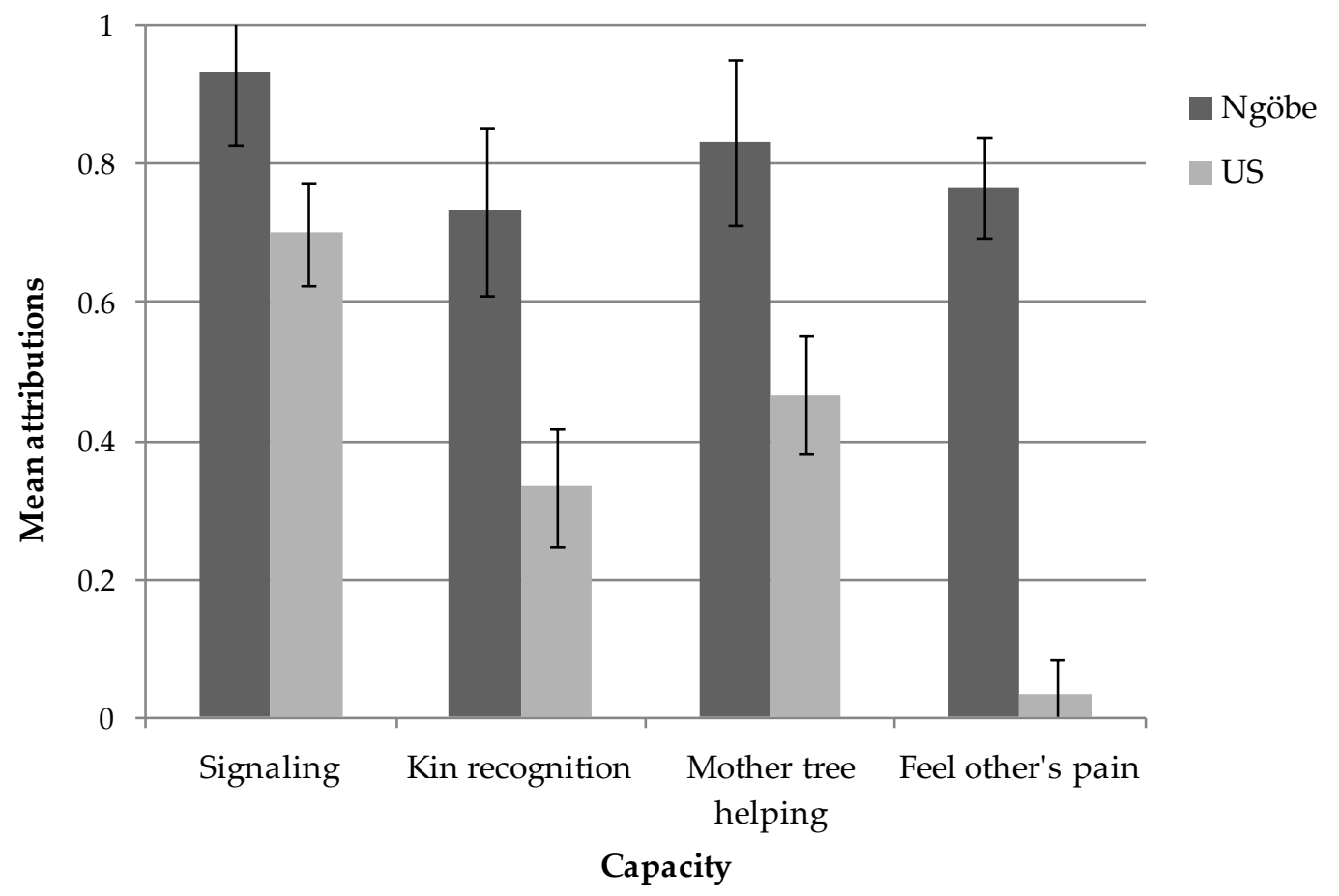

These results provide converging evidence for the key findings from Experiment 2A.

Most US and Ngöbe participants agree that plants are capable of communicative signaling, but kin recognition, resource sharing, and feeling another plant's pain.

\subsection{Experiment 2: Discussion}

In Experiment 2, we found converging evidence from action predictions and capacity inferential reasoning about actual plant behavior. 


\section{Language}

We conducted exploratory analyses of language differences in the capacity attribution tasks in both Experiments $1 \mathrm{~B}$ and $2 \mathrm{~B}$ to assess whether these different predicate assignment patterns reflect cross-linguistic differences among Spanish, English, and Ngöbere. If attribution patterns hold across languages within each of our cultural samples, then this would offer preliminary evidence that cultural differences in capacity attribution do not merely reflect linguistic artifacts. ${ }^{14}$

The US sample included 16 bilingual English-Spanish speakers, of whom 12 completed the study in Spanish and 4 in English (see Appendix B). An additional 18 English speakers rounded out our US English sample (for $n=22$ ). In Panama, all participants spoke Spanish and Ngöbere (most with bilingual fluency levels), so approximately half completed each set of tasks in Ngöbere ( $n=13$ in Exp. $1 ; n=11$ in Exp. 2$)$ and the other half in Spanish $(n=10$ in Exp. $1 ; n=6$ in Exp. 2). Language assignment was sometimes based on considerations of language proficiency; otherwise participants were randomly assigned to a language condition. Language could not be randomly assigned in the US due to the small number of bilingual participants.

Results. There were no reliable language effects of Spanish versus English among US participants, or for Spanish versus Ngöbere among Ngöbe participants. This indicates that the attribution of capacities such as wanting, feeling, or communicating to plants is unlikely to be a linguistic artifact. These results must be interpreted with caution given our modest sample sizes and nonrandomized language assignment. Nonetheless, they provide preliminary evidence that agency attributions are not solely dependent on language for either Ngöbe or US participants.

\footnotetext{
${ }^{14}$ We did not expect that language would affect the action prediction tasks (Experiments 1A and 2A), which rely on predictions of one or another outcome rather than interpretations of particular predicates. Action scenarios intentionally used neutral event descriptions that avoided the critical agency terms in question (i.e., no references to want, kin altruism, communicate, etc.).
} 


\section{Detecting multiple conceptual models}

In this section we consolidate our findings from the above experiments by using cultural consensus modeling to address several critical questions. One outstanding question concerns the nature of conceptual divergence between US and Ngöbe views of agency. One could argue that the cultural mean differences in agency attribution do not decisively demonstrate two distinct conceptual models. For instance, Ngöbe attributions for the various agency capacities in Experiment $1 \mathrm{~B}$ are not consistently near ceiling for plants as they are for animals, raising the possibility that Ngöbe respondents share the basic animal-oriented model of US participants but are simply more likely to endorse scattered capacities for plants. In other words, the mean differences between US and Ngöbe responses could represent variation from a single (universal) model of agency that is animal-oriented, rather than pointing to a distinct model where agency is equally a property of plants and animals. Another important question concerns the sources of individual variability that contribute to these differences both within and across cultures.

To answer these and related questions, we used a new bottom-up cultural consensus modeling method to identify whether multiple conceptual models of agency are latent in participant responses (collapsing across US and Ngöbe participants), and to explore betweenand within-culture variations on these conceptual models. Our modeling is conducted on data from both capacity attributions and action predictions across the two experiments for a comprehensive assessment of agency frameworks. Our first objective was to determine if there are one or more consensus conceptual models present among our respondents. This is an important step beyond the cultural differences reported above because two groups can differ even while one group fails to converge on a consensus model (Le Guen et al., 2013). If more than one consensus is detected this will indicate that multiple models are present. Second, we are interested in the agency attribution profile of each consensus model, which can answer the key 
676

677

678

679

680

question of whether or not there is an alternative model that consistently endorses plant agency on par with animals. Third, we are interested in how participants cluster into the consensus models according to their actual cultural membership and individual characteristics, as well as how individual-level variables may predict competence within each model. This will enrich understanding of across- and within-group variability and point to individual factors that may influence one's conceptual model of plant agency.

\subsection{Cultural consensus modeling}

Cultural consensus modeling (CCM) (Romney et al., 1986) has been applied extensively in prior cultural research on biological cognition (Atran \& Medin, 2008; Medin et al., 2007). Conceptually similar to factor analysis, CCM determines if a single underlying model exists, as well as whether patterns of residual agreement beyond the overall consensus suggest additional models that hold for subgroups in the sample. Each participant is assigned a cultural "competence," where higher scores on a factor loading indicate that an individual's responses are closer to the cultural consensus. CCM also calculates the consensus model "answer key" with a competency weighted consensus rating for each item, providing a more reliable approximation of the common truth than traditional data aggregation techniques (France \& Batchelder 2014).

Recent advances in CCM provide a model-based way to derive multicultural consensus from continuous response data (Anders et al., 2014). This new Bayesian inferential approach to consensus modeling (Anders, 2013) offers a key advantage over prior CCM techniques by treating culture as a latent variable and using a bottom-up approach to identifying distinct consensus models and their members (rather than relying on known cultural membership as in traditional CCM methods). This confers a theoretical advantage over statistical models that treat culture as a fixed independent variable, by focusing on conceptual models and allowing cultural membership to remain latent. To emphasize this analytic distinction, we refer henceforth to 
700 "conceptual/consensus models" rather than "cultural models." CCTpack also introduces a new response precision parameter to assess whether some items are more difficult than others, unlike traditional CCM methods that assume all items are equally difficult.

\subsection{Methods and procedure}

Using the CCTpack R software package (Anders, 2013), we applied the Bayesian CCT model to the combined capacity attributions from Experiments 1 (5 individual capacities for each of 4 kinds) and 2 (4 plant social capacities) and action predictions from Experiment 2 only (4 plant social interaction predictions) (total $\mathrm{k}=28$ ). Experiment 1 action predictions were not included because they were confounded by experimental condition. The participant-level response data from all US and Ngöbe participants together $(N=47)$ were subjected to cultural consensus modeling for a 47 (participants) X 28 (items) matrix. For clarity, results are presented at the item level for plants but the kind level for the other nonhuman kinds (as in Figure 6). In CCTpack, two posterior predictive checks are used to compare which model best fits the actual data. 1 . To check that the consensus structure of the data is appropriately fit by the model (i.e., the appropriate number of consensuses), a scree plot of eigenvalues assesses the fit between the model-generated estimates and the actual structure of the data (see Royce, 2013 for details). 2. To check whether the item difficulty parameter should be treated as uniform (i.e., homogenous item difficulty) or variable (i.e., heterogeneous item difficulty), a variance dispersion index (VDI) reports how well the model captures differences across items due to response variability; these VDIs are compared and the model with better fit is selected (see Anders et al., 2014). 
Figure 6. Consensus models for agency of plants and other nonhumans

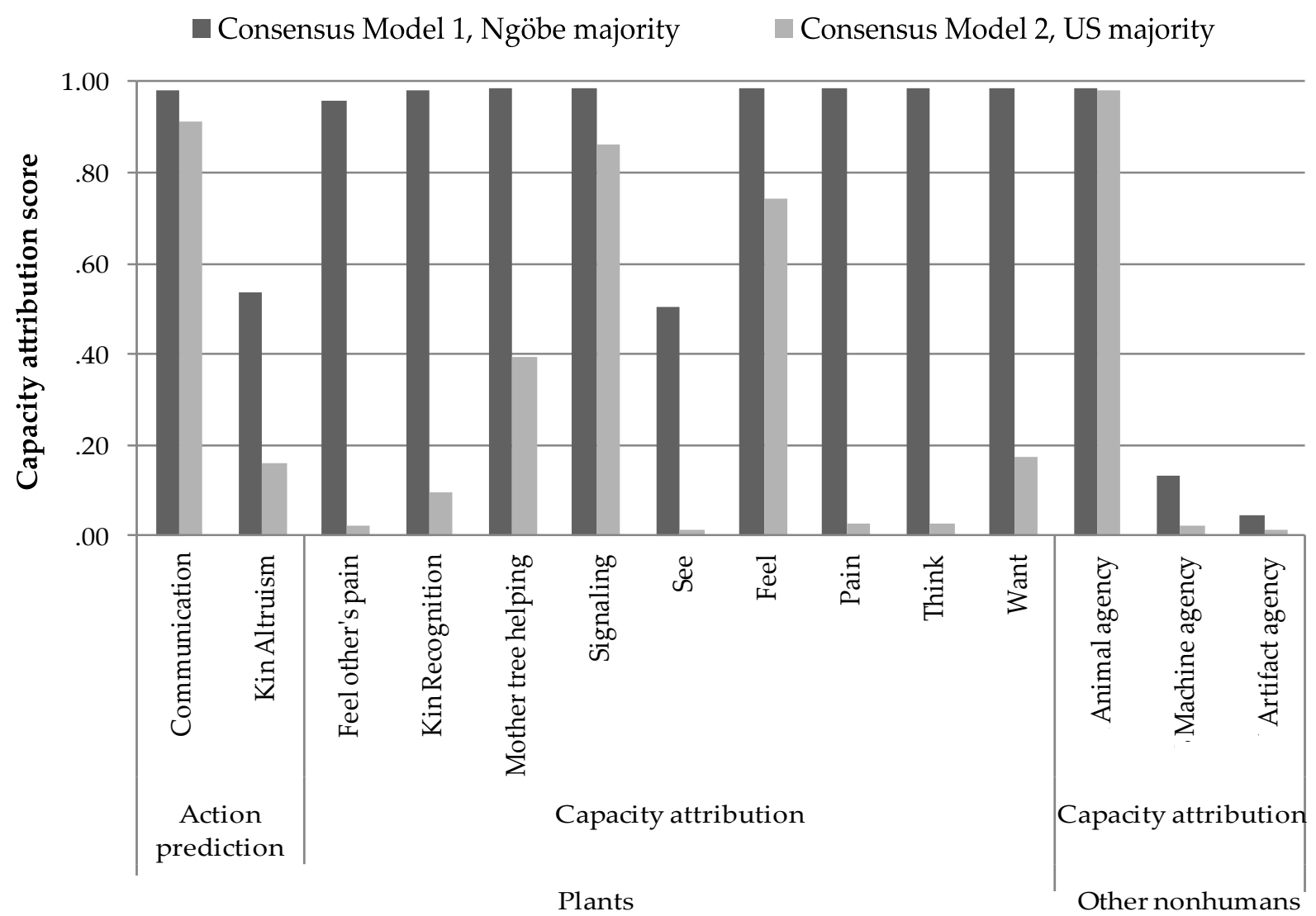

*Total capacity attributions for other nonhumans are an average of 5 capacities: see, feel, feel pain, think, want

The data were simulated using a series of models with 1, 2, and 3 consensuses, with and

without heterogeneous item difficulty.

Item difficulty. The VDI check for item difficulty indicated that a model assuming

homogeneous item difficulty fit the data, whereas a model with heterogeneous item difficulty failed to fit the data. ${ }^{15}$

Consensus fit. The scree plots of eigenvalues showed that the first factor was substantially larger than subsequent factors, with a second factor evident but less pronounced. Posterior predictive checks showed that the data structure was well fit by both a one- and two-consensus

\footnotetext{
${ }^{15} \mathrm{~A}$ model that assumed heterogeneous items difficulty was unable to reach convergence of modeling chains for a successful fit to the data (Anders, 2014).
} 
731

732

733

734

735

736

737

738

739

740

model, but a three-consensus model failed to fit the data. ${ }^{16}$ This suggests an overarching consensus accompanied by two subgroups. The overall consensus was expected due to the substantial agreement on capacity attributions for animals, machines, and artifacts. A twoconsensus model would be expected to pick up additional variability concerning plant agency. In the past, we have consistently found a good overall consensus paired with systematic subgroup differences (Medin, et al., 2007). Thus, we selected a two-consensus model with homogeneous item difficulty.

\subsubsection{Consensus Models}

The model identified two consensuses latent in the agency rank responses (see Figure 6).

With respect to the question of whether there are two different models for plant agency, the results are unambiguous. The first consensus model presents a strong and consistent endorsement of the nine plant capacities for social and intentional agency. Indeed, with the exception of seeing, capacity attributions to plants and animals are indistinguishable (at or near ceiling). With respect to action predictions, inferences for kin altruism were lower than would be expected given that the associated capacities (kin recognition, mother tree helping) are strongly

endorsed. This indicates that the kin altruism prediction scenarios may have tapped other considerations for these participants (e.g., resource sharing weighed against access to sunlight in the mother tree scenario). The second consensus model presents a highly selective endorsement of plant agency. Beyond a capacity to signal and feel, plants are not viewed as having much agency and are clearly less agentic than animals.

\subsubsection{Consensus model membership}

Consensus group membership. The model detected and clustered individual participants into the two consensus models in close correspondence with actual cultural membership.

\footnotetext{
${ }^{16}$ A 3-consensus model was unable to reach convergence of modeling chains (Anders, 2014), indicating that there were no detectable third components and/or too many degrees of freedom.
} 
754 Members of the plant-oriented Model 1 were primarily Ngöbe respondents (9 of 11) whereas

755 members of the animal-oriented Model 2 were primarily US respondents (28 of 36 ). The

756 remaining members of each model were from the other cultural group. Individual differences in consensus model membership. Ngöbe. The Ngöbe sample exhibited substantial clustering variability (9 clustered with Model 1, 8 with Model 2), which may speak to the presence of multiple models of agency that correlate with particular individual characteristics.

Based on prior research, we anticipated that Ngöbe members of the plant-oriented Model 1

would lead more traditional community-based lifestyles than Model 2 members, as indexed by three demographic measures (Indigenous church membership, age, formal schooling). Consistent with our prediction, members of Model 1 were more likely to be members of the Indigenous church, whereas members of Model 2 were more likely to be Evangelical churchgoers or nonattendees, $F(1,15)=5.79, p=.05, \eta^{2}=.28$. Model 1 members also tended to have fewer years of formal schooling, $F(1,15)=3.33, p=.09, \eta^{2}=.18$, and were more likely to be male, $F(1,15)=3.33, p$ $=.09, \eta^{2}=.18$, but these trends only approached significance..$^{17}$ In addition to individual characteristics, we also checked to see whether any task factors were associated with model membership. Importantly, task language (Ngöbere or Spanish) did not differentiate between members of Model 1 and 2. This provides further evidence that these conceptual models of agency are unlikely to reflect linguistic differences between Spanish and Ngöbere. However, Model 1 members were more likely to be in the culture-specific stimulus version of Experiment $1, F(1,15)=6.48, p<.05, \eta^{2}=.31$. As noted earlier, assignment to this version was incidentally correlated with other demographic factors, so the significance of this finding is unclear.

\footnotetext{
${ }^{17}$ Note that age did not correlate with model membership among Ngöbe, suggesting that age is not a primary factor in these conceptual differences among our Ngöbe sample. This is a useful observation in light of any potential concerns regarding the age differences between our Ngöbe and US samples.
} 
US. US participants clustered heavily into a single model (28 of 30 with Model 2), which

limited analysis of differences between Model 1 versus Model 2 members due to the small sample (Model $1 n=2$ ). Unsurprisingly, we found no reliable differences in model membership by either individual characteristics or task language. On the other hand, it is a notable finding that US members converged so strongly on a single model of agency despite being the larger sample and being drawn from two distinct language samples.

Conceptual differences in cross-model membership. Given that a cultural majority emerged for each consensus model, we were interested in the responses of those individuals who were crossclustered with the other consensus model (i.e., that of their non-majority culture). The agency attribution profiles of these subgroups could speak to what happens at the boundaries of each conceptual model. All differences reported below were significant at the $p<.05$ level in MANOVA's comparing agency attribution measures across the two models separately for each culture.

Ngöbe participants who clustered with the US-majority Model $2(n=8)$ diverged from their Ngöbe Model 1 counterparts in their lower attributions of agency to plants (on every capacity except mother tree helping), as well as their lower endorsement of machine agency capacities. However, they remained distinct from US members of Model 2 by being more likely to endorse a plant's capacity to feel another tree's pain. Ngöbe and US Model 2 members did not reliably differ on any other measures of plant agency, indicating a fair amount of convergence between this subgroup of Ngöbe participants and the US-majority model.

The two US participants who clustered with the Ngöbe-majority Model 1 differed from their US Model 2 counterparts in their higher endorsement of plant agency (for kin recognition, and all five intentional agency capacities: see, feel, pain, think, want). They remained distinct 
from Ngöbe members of Model 1, however, by being less likely to endorse plants' capacity to experience pain or feel another tree's pain.

These findings lend additional evidence for multiple models of agency among Ngöbe respondents. The focal model among Ngöbe respondents presents a strong recognition of plant agency, but this is accompanied by pronounced variation towards an animal-oriented model where plant agency is diminished. For their part, the rare US individuals who departed from their group's dominant animal-oriented model of agency moved towards an increased recognition of plant intentional (more so than social) agency. Individual differences in competence. One unique strength of CCM is that it goes beyond sample means to assess each individual's level of competence on their consensus model, or how well they fit the consensus model to which they were assigned. We next analyzed individual differences associated with these competence scores. Analyses were run separately for Model 1 and Model 2 scores within each cultural group (Ngöbe or US).

For Ngöbe participants, we anticipated that greater competence on the plant-oriented Model 1 would correlate with more traditional community-based lifestyles, whereas competence on the US-majority Model 2 would show the inverse. However, no reliable relationships emerged between competence and lifestyle characteristics for Ngöbe clustered with either Model $2(n=8)$ or Model $1(n=9)$, likely due to modest sample sizes.

For US participants clustered with the US-majority Model 2, the only individual characteristic that reliably correlated with competence was, unexpectedly, gender, such that males were more competent than females $(r=.54, p<.01)$. It is unclear why this may be the case. Further investigation showed that competence among US participants exhibited interesting conceptual patterns. US members' competence on Model 2 was associated with more predictions for kin altruism but fewer predictions for communication, whereas neither inference 
task predicted US membership in Model 1 versus Model 2-instead, membership on Model 1 was associated with greater plant agency attributions. This suggests that plant agency concepts break down into separate components that may track different individual characteristics among US participants. We pursued this by exploring individual characteristics associated with plant agency measures among the entire US sample $(n=30)$. Interestingly, religious belief correlated with greater willingness to ascribe agency capacities to plants (specifically, thinking and wanting), $\mathrm{F}(1,25)=4.65, p<.05, \eta^{2}=.16$, whereas growing up in a nonurban environment correlated with greater predictions for plant social interaction (specifically, communication), $\mathrm{F}(1,25)=4.16, p$ $=.05, \eta^{2}=.14$. These separate patterns for US religiosity and childhood residence suggest that knowledge of plant behavior may track separately from interpretive frameworks for understanding that behavior.

\subsection{Cultural modeling: Discussion}

Cultural consensus modeling allowed us to identify whether multiple conceptual models of agency are present among our respondents using a bottom-up modeling approach that treats culture as a latent variable. Two distinct consensuses were detected, confirming that there are two qualitatively distinct conceptual models of agency. One model endorses an animal-oriented view of agency where plants possess a very constrained set of capacities for signaling and sensation (endorsed by the majority of US respondents and nearly half of Ngöbe respondents). But an alternative model also stands, one that takes a decidedly different view where plants possess a robust suite of agency capacities on par with animals (endorsed by a majority of Ngöbe informants and two US respondents). These results provide evidence against the claim that all individuals share a basically animal-oriented model of agency, while also highlighting that multiple conceptual models are available within a given cultural context. 
Investigation of the individual characteristics aligned with these models further

illuminated the sources of variation underlying diverse conceptual stances. The results suggest

with greater predictions for plant social interactions. This suggests that epistemological

orientations (e.g., religion) may influence interpretative frameworks for plants while familiarity with the biological world may inform inferences about actual plant behavior.

\section{General discussion}

\subsection{Summary}

Across two experiments using mixed methods, we found that Ngöbe were more likely models of agency.

points to a framework that interprets plant and animal actions on closely corresponding terms.

866 This challenges the domain-specificity claim that plants are universally conceptualized as

867 insentient objects that belong to a different domain than animate agents. Second, the Ngöbe view

868 correlates with insightful inferences about plant social behaviors that have only recently been

869 observed by Western plant scientists (Mancuso \& Viola, 2015). This suggests that the Ngöbe 
870

perspective on plants as active agents may afford insights into complex plant behaviors that are less accessible on the US view of plants as insentient, passive biological kinds.

Clearly, many Ngöbe informants conceptualize plants as agents in a way that US individuals do not. The critical question is how to understand the conceptual commitments at stake in these observed cultural differences. In what follows, we consider three possible accounts of the present findings in terms of (1) different degrees of ecological expertise, (2) extensions of universal folkpsychology concepts, or (3) culturally variable concepts of agency.

\subsection{Ecological expertise}

One might argue that Ngöbe inferences for plant social behaviors can be explained by their greater ecological knowledge as compared to US college students, rather than resulting from distinct conceptual frameworks per se. Certainly Ngöbe can be expected to have considerable knowledge of plants through their daily interactions with the surrounding forest ecology. However, Ngöbe informants' predictions for plant communication and kin altruism cannot be explained solely by expertise because these specific social interactions represent recent discoveries in Western botanical science. If sheer quantity of experience with plants led Ngöbe to observe subtle signaling and kin resource sharing behaviors, then this begs the question of why those insights eluded Western plant scientists for centuries. We suggest that the Ngöbe conceptual framework provides a lens for expecting complex behavior which guides their inferences even in novel situations such as these. Converging evidence that cultural frameworks guide inferences for novel cases of nonhuman behavior comes from another study where we found that Ngöbe are more likely than US individuals to accurately infer cooperation among two animal predators that are unfamiliar to them (ojalehto, Medin, Horton, et al., 2015).

It is important to ask how ecological expertise and concepts of nonhuman agency may interact, but the answer is unlikely to be as simple as expertise versus conceptions. We see 
894 interpretative frameworks for plant agency (whether encoded in folktheories or scientific

895 theories) as important conceptual devices for organizing knowledge and integrating new

896 information (Hall, 2011; Narby, 2006), as well as guiding inference and explanation (Keller, 1983;

897 Medin \& Bang, 2014). From this perspective, conceptual frameworks necessarily involve feedback

898 with many forms of cultural experience including ecological knowledge. In this regard, it is

899 informative to consider how Western scientists have brought their own intuitions to the study of

900 plant behavior. For instance, initial findings for plant kin recognition were met with skepticism

901 among plant scientists and some even declared (dubiously) that it would be "extraordinary" if

902 the early claims could actually be substantiated (Klemens, 2008, p. 67). Those claims have since

903 been substantiated to the satisfaction of many in the field (Bhatt, et al., 2011; Biedrzycki \& Bais,

904 2010). Yet the initial skepticism serves to highlight how even experts' inferences concerning plant

905 behavior may reflect prior assumptions-ecological expertise is not independent of cultural

906 intuitions. Our results serve as a critical first proof that those cultural intuitions do differ.

907 Our findings align with broader interdisciplinary research programs demonstrating that

908 Indigenous perspectives contribute novel insights into biological and ecological structure

909 (Anderson, 2012; FORMABIAP, 2008; Narby, 2006; Pierotti, 2011; Pitman et al., 2011; Waldstein \&

910 Adams, 2006). Such observations and our own results raise important questions concerning the

911 interactions between ecological expertise and cultural epistemologies as they relate to concepts of

912 nonhuman agency and environmental cognition more broadly (e.g., ojalehto, et al., 2015; ojalehto

913 et al., 2013). With cultural differences now established by the present experiments, further work

914 may begin exploring how varying levels of expertise within each cultural context may (or may

915 not) influence conceptions of natural agents. 


\subsection{Folkpsychology}

Our results could be interpreted as showing that Ngöbe overextend a folkpsychological concept of mind to plants (e.g., Atran \& Norenzayan, 2004; Barrett, 2000; Boyer, 1996, 2003). This overextension account would rest on the assumption that Western folkpsychology is a universal conceptual framework whose proper domain is restricted to animate agents, defined as humans and animals (e.g., Sperber \& Hirschfeld, 2004; Wellman \& Gelman, 1992). On this perspective, Ngöbe are incorrectly inferring human-like mental states on the part of plants. If the current results are interpreted in this way two questions follow. First, if the Ngöbe conception of plant agency affords useful insights into plant behavior then is it appropriate to characterize it summarily as a mistaken inference? Related to this, we must also consider why the US folkpsychological stance leads to the misguided rejection of actual plant capacities for social behavior.

Considering these questions, we propose that US attitudes about plants may be interpreted as an under-extension of agency concepts that are constrained by cultural beliefs about brains and nervous systems (for related points, see Marder, 2012; Marder, 2013). The idea that anthropocentric folkpsychology represents a selective narrowing of the agency domain would be consistent with several lines of evidence. First, based on infancy studies, it has been suggested that the extension of the concept "agent" is defined by principles of interaction (e.g., goal-directedness) and has no proper ontological domain (Gergely \& Csibra, 2003; see also Lowder \& Gordon, 2015). This has led some to propose that the core representational system for agency actually has no proper intuitive ontological domain: “Our tendency to apply psychological explanations to non-human phenomena (see Piaget, 1929; Heider \& Simmel, 1944) may not be due to an overextension of an (originally more restricted) psychological interpretational framework," but may instead reflect the proper application of a teleological 
stance (Csibra et al., 1999, p. 265). (We agree but hasten to add that a psychological framework need not be the only possible one for understanding teleological nonhuman phenomena.) Given that plants exhibit the critical cues for agency perception (e.g., goal-directedness, contingent interaction), they would also fall within the proper application of this teleological stance.

Furthermore, the evidence suggests that culture plays a role in acquiring an anthropocentric folkpsychology constrained to humans and animals. A large body of work in developmental psychology indicates that infants possess a core representational system for agency online by the end of the first year of life (Bíró \& Leslie, 2007; Csibra \& Gergely, 2013; Johnson, 2003; Johnson et al., 2007; Woodward, 2013). However, this is a skeletal representation system and it is only later on that children develop a rich conceptual framework for agency that includes causal principles tied to minds and mental states, where behavior is understood on folkpsychological terms (Johnson, 2000; Wellman, 2010). For US children, learning that psychological properties should not be extended to all actors who exhibit goal-directed behavior (such as plants or other inanimate nonhuman kinds) but rather selectively applied to humans and other animals requires extended learning into the grade school years (Opfer, 2002). This indicates that the exclusion of plants from the domain of agency may be a culturally acquired stance. In short, the developmental evidence is consistent with the possibility that anthropocentric folkpsychology represents a culturally acquired lens on agency that narrows the domain to animates on the basis of a human prototype. The corresponding folkpsychological notions of minds and mental states may reflect a cultural model among Western researchers and participants (for similar conclusions in related domains, see Medin et al., 2015). This raises the possibility that the infant's representational system for agency - while widely seen as a precursor to folkpsychology among Western samples - may serve as a precursor to alternative folktheories of agency in other cultures. This is especially plausible when we consider that capacities which 
cue agency detection (goal-directed motion, contingent interaction) are not exclusive to entities with human-like brains but are also carried out by plants and other organisms (Chamovitz, 2012; Marder, 2012; Uexküll, 2010). Yet by focusing on the specifically psychological aspect of agency as it is assumed on Western folktheories, researchers have rarely considered the possibility that cultural folktheories of agency may be organized around other, non-psychological concepts (for a notable exception in the domain of folksociology, see Hirschfeld, 2006; Hirschfeld, 2013). Considering this possibility allows alternative accounts to be considered.

\subsection{Folkcommunication}

It is possible that the current findings point to a distinctive conceptual framework for agency that is available to Ngöbe informants. Specifically, we have argued that Ngöbe endorsements of plant agency can be understood in terms of folkcommunication, where the capacity for relational interaction is the grounds for inferring agency. This framework would properly apply to diverse actors including (at least) plants and animals. This account locates cultural variation at the level of conceptual organization of folktheories rather than in variable extensions of universal folkpsychological concepts. Folkcommunication is at least as compatible with the data as an explanation based on overextensions of folkpsychology. Furthermore, folkcommunication carries the advantage that it makes fewer assumptions about mental-state concepts presumably by Ngöbe, and thus avoids the explanatory paradox of why Ngöbe would consistently make "category errors" concerning plants despite having considerable ecological experience. On folkcommunication plant agency attributions are seen as an empirically grounded recognition of communicative exchanges among diverse natural kinds.

We propose that folkpsychology and folkcommunication, while likely deriving from a common early-developing cognitive system for detecting agency (Csibra, et al., 1999; Johnson, 
2003), follow distinctive meaning-making principles that ultimately lead to different domains.

This need not imply that the two folktheories are mutually exclusive, such that US individuals have no access to folkcommunication, for instance. Indeed, our cultural consensus modeling results show that both models are present in the Ngöbe context and possibly in the US context as well. We speculate that either conceptual framework may be cultivated to a differing degree in various cultural contexts. Even within a single individual, these folktheories could represent interpretive stances that focus on distinct properties of agency. On folkcommunication, the focus is on relational interactions as the primary quality of agency, and mental states may play a secondary role if any in agency judgments. By contrast, the folkpsychological lens trains attention to mental states as the primary property of agency and if communication figures in this model, it may be seen as a derivative property of the mental (Dennett \& Haugeland, 1987).

Our account is roundly consistent with evidence from related domains to suggest that Western anthropocentrism leads to patterns of reasoning that differ from a more ecological orientation among Indigenous communities (Atran et al., 2005; Bang et al., 2007; ojalehto, et al., 2013; Waxman \& Medin, 2007), and resonates with other research proposing that broad framework principles in the folkpsychological domain may recruit different bodies of socially learned knowledge across cultures (Meltzoff \& Gopnik, 2013, see also Gelman, 2009). It is also well supported by a growing body of anthropological evidence on indigenous folktheories of communication in ecosystems (see especially Kohn, 2013, 2015).

The current experiments are an initial foray and many questions remain. To date, folkpsychology has been virtually the only framework in town for thinking about agency, so it requires future work to clarify the inferential principles and explanatory constructs at work in folkcommunication. One line of investigation could target cultural differences in attributions of predicates and inferences that might distinguish between folkpsychology (e.g., internal 
1012 individual states) and folkcommunication (e.g., interactive relational states). Cultural diversity

1013 may arise from differences in the relative salience given to these conceptual nodes and their

1014 extension to different classes of agents (e.g., plants, abiotic kinds, social groups, artificial

1015 intelligence).

1016 12. Conclusion

Our research project sought to explore variability in concepts of nonhuman agency,

1018 specifically plant agency, and to generate new forms of evidence that can speak to the conceptual

1019 commitments at stake in animism. Our experimental results show substantial cultural variation

1020 in concepts of plant agency and demonstrate that the Ngöbe perspective affords sophisticated

1021 insights into plant behavior. Our converging methods extend prior work by observing systematic

1022 differences in nonhuman agency attributions across cultures, establishing that these cultural

1023 differences extend to inferential reasoning, and showing that these cultural patterns arise from

1024 two distinct conceptual models of agency rather than variations on a single universal model. The

1025 differences observed between US and Ngöbe informants may arise from different extensions of a

1026 common folkpsychology, or from a distinctive theory of folkcommunication among Ngöbe

1027 informants. The present results are suggestive of the latter possibility but it remains for future

1028 research to disentangle these accounts.

1029 At the very least, these findings raise the possibility that domain-specific conceptual

1030 knowledge may be organized in ways that are culturally variable. The anthropocentric stance on

1031 folkpsychology as the key organizing principle for agency may be a feature of Western cultural

1032 epistemologies rather than a universal cognitive principle. As an alternative, folkcommunication

1033 offers an ecologically oriented lens for attending to complex forms of interaction among

1034 nonhuman agents. The Ngöbe perspective serves as an invitation to revisit the widespread

1035 assumption among Western researchers that mentalistic folkpsychology is the universal intuitive 
1036 prototype for agency - and that plants belong outside this domain. Pursuing the invitation to reconsider anthropocentric views of agency could advance cognitive theory while expanding

1038 Western understandings of nonhuman actors. The question of how humans conceptualize

1039 nonhuman beings in their ecological communities has never been more relevant than it is today. 
1040

1041

1042

1043

1044

1045

1046

1047

1048

1049

1050

1051

1052

1053

1054

\section{Acknowledgements}

We thank the Ngöbe community for their support of and participation in this research.

We are grateful to Eugene Anderson, Daniel Casasanto, Rumen Iliev, Joshua Knobe, Jonas Nagel, Jeremy Narby, Ara Norenzayan, Jeremy Ojalehto, Lance Rips, Sonya Sachdeva, Rebecca

Seligman, Richard Shweder, Sandra Waxman, and two anonymous reviewers for helpful discussion of these ideas. Thanks to John Opfer for generously sharing the materials used in Experiment 1, and to Royce Anders for sharing his expertise on cultural consensus modeling. For their contributions to data collection and analysis we thank Linda Flores and Yereida Gallardo. Portions of this research were presented at the Cognitive Science Society Meeting in Pasadenda, CA in July, 2015; the Society for Anthropological Sciences Meeting in Pittsburgh, PA in March, 2015; and the University of Chicago Cognitive Brownbag in February 2015. The research and writing of this article was supported by the National Science Foundation under Grant Numbers NSF DRMS 1427035 to bethany ojalehto and Doug Medin, SES0962185 and DRL1114530 to Douglas Medin, and an NSF Graduate Research Fellowship to bethany ojalehto. 
1055

1056

1057

1058

1064

1066

1067

1068

1069

1070

1071

1072

1073

1074

1075

1076

1077

\section{Appendices}

\section{Appendix A: Experiment 1}

\section{A1. Experiment 1A: Supplementary methods and materials}

Culture-specific stimuli for plants and machines were provided in Panama, as follows:

Plant item (Benefit Present condition): Here is a plant that grows on the ground. This kind of plant depends on sunlight to grow and live. The seedling is starting to grow in the shade, here. The sunlight is over there. When this plant grows, will it keep growing straight forward in the shade, or will it grow over to where the sunlight is? Aquí hay una planta que crece en el suelo. Esta planta necesita luz del sol para poder crecer y vivir. La semilla esta empezando a crecer aquí, en la sombra. La luz del sol esta justo ahí. ¿Cuándo esta planta crezca, se mantendrá creciendo recto debajo del sombra, o crecerá hacia donde está la luz?

For machines, we used line drawings of three familiar machines (motorboat, radio, and chainsaw) to replace the original novel machines $(N=10)$. Otherwise, all aspects of the machine stimuli were conserved (i.e., locomotion, goal objects). (Culture-specific machine items are available from the first author upon request.)

\section{A2. Experiment 1B: Supplementary methods and materials}

Question probes for capacity attributions as translated into each study language (English, Spanish, and Ngöbere) are provided below, using as an example item the plant growing toward sunlight. Each probe was phrased in relation to the goal object (e.g., can a plant see, want, feel, or think about the sun?), with the exception of pain, which specified a form of harm (e.g., cutting a plant). As such, each capacity attribution represented an interpretation of that entity's specific goal-directed action presented in the task. This method follows that used in Opfer \& Gelman's 
1078 original study, with the exception of wanting (which was phrased with the object "anything"

1079 rather than the goal object).

$1080 \quad$ Can the plant want the sun?

$1081 \quad$ ¿La planta puede querer el sol?

1082 Ngwina trö törö köteri gwande dba töin iye ya? (Si hay luz del sol adentro, ella puede ver la

$1083 \quad$ luz?)

1084

1085 Can the plant feel the sunlight when it touches it?

$1086 \quad$ ¿La planta puede sentir el sol cuando la toca?

1087 Ngwina trö törö köteri goane dba doin iye ya? (Si hay luz del sol adentro, ella puede sentir la

$1088 \quad$ luz?)

1089

1090 If it's cut, can the plant feel pain?

$1091 \quad$ ¿Si se corta, esta planta puede sentir dolor?

1092 Mö we dö ködrete jödrónbidi gwane, dba nme tare iye ya? (Si usted la puyas con algo, ella

$1093 \quad$ puede sentir dolor?)

1094

$1095 \quad$ Can the plant think?

$1096 \quad$ La planta puede pensar?

1097 Dba töbike? (Ella puede pensar?)

1098

$1099 \quad$ Can the plant see the sunlight?

$1100 \quad$ ¿La planta puede ver la luz del sol?

1101 Dba tönme todroin? (Ella puede querer algo?) 


\section{A3. Experiment 1B: Supplementary results}

1103

1104

1105

1106

1107

1108

1110

1111

1112

1113

1114

1115

1116

1117

1118

1119

1122

1123

1124

1125

Missing item response. Due to experimenter error, six US participants were presented with the "want" question for only 2 of 3 plants. Their average "want" attributions to plants were collapsed over 2 rather than 3 items (this was warranted as responses were uniform for both plant items for all 6 participants).

Results. In addition to the cultural differences reported in the main text, we found the expected main effects and interactions (as evident in Figures 1 and 2 presented in the main text); descriptive statistics are provided in Table A1 and tests are reported in Table A2. Main effects: There were main effects of kind (animals > plants $>$ machines $>$ artifacts, all $p s<.01$ ) and of capacity (feeling and wanting were the most frequent attributions, $p s<.01$, and pain more than seeing, $p<.01)$. Condition: As expected, BP/BA condition had no effect on psychological attributions for either group.

Interactions: In addition to cultural differences in capacity attribution to plants (see main text), cultural differences of lesser magnitude also emerged for the three other kinds. Animals: Ngöbe were more likely than US participants to attribute seeing to animals. Inspection of US explanations indicated that situational features of task scenarios prompted infrequent denials that an animal could see the goal object (one was in the animal's mouth; another was inside a log). Machines: Ngöbe were more likely than US participants to attribute pain and wanting to machines. Artifacts. Ngöbe were also more likely than US participants to attribute feeling and wanting to artifacts. These cultural differences were minor in the absolute sense, and attributions to machines and artifacts were low even among Ngöbe.

Ngöbe culture-specific plant stimulus: Among Ngöbe participants, capacity attributions to plants unexpectedly differed across the two stimulus versions, such that participants were more likely to attribute agency capacities to the culture-specific item depicting an outdoor ground vine 
$1126(M=.86, S E=.09)$ than the original study item from Opfer \& Gelman (2001) depicting an indoor

1127 potted plant $\left.(M=.45, S E=.08), F(1,21)=11.44, p<.01, \eta^{2}=.35\right)$. As we found for Exp. 1A goal-

1128 directed action predictions, however, this effect held for all three plant stimuli (not just the item

1129 that differed across versions), so other factors (e.g., participant schooling and church

1130 membership) contribute to the observed difference.

1131 Table A1: Mean attributions of agency capacities by culture and kind for Experiment 1B

\begin{tabular}{|c|c|c|c|c|c|c|c|c|c|c|}
\hline \multirow{2}{*}{ Psychological capacity / Culture } & \multicolumn{2}{|c|}{ Animals } & \multicolumn{2}{|c|}{ Plants } & \multicolumn{2}{|c|}{ Machines } & \multicolumn{2}{|c|}{ Artifacts } & \multicolumn{2}{|c|}{ Capacity Total } \\
\hline & Mean & $S D$ & Mean & $S D$ & Mean & $S D$ & Mean & $S D$ & Mean & $S D$ \\
\hline \multicolumn{11}{|l|}{ Feel } \\
\hline Ngöbe & .97 & .10 & .84 & .36 & .33 & .37 & .23 & .31 & .59 & .29 \\
\hline US & .98 & .08 & .69 & .32 & .16 & .31 & .02 & .08 & .46 & .20 \\
\hline Total & .98 & .09 & .75 & .34 & .23 & .35 & .11 & .23 & .52 & .25 \\
\hline \multicolumn{11}{|l|}{ Want } \\
\hline Ngöbe & 1 & .00 & .78 & .37 & .35 & .41 & .13 & .28 & .56 & .26 \\
\hline US & .95 & .12 & .37 & .47 & .13 & .30 & .01 & .06 & .36 & .24 \\
\hline Total & .97 & .10 & .54 & .48 & .22 & .36 & .06 & .19 & .45 & .28 \\
\hline \multicolumn{11}{|l|}{ Pain } \\
\hline Ngöbe & .97 & .10 & .71 & .44 & .16 & .35 & .10 & .25 & .49 & .28 \\
\hline US & 1 & .00 & .08 & .22 & .00 & .00 & .01 & .06 & .27 & .07 \\
\hline Total & .99 & .06 & .34 & .45 & .07 & .23 & .05 & .17 & .36 & .23 \\
\hline \multicolumn{11}{|l|}{ Think } \\
\hline Ngöbe & .83 & .39 & .46 & .50 & .09 & .29 & .07 & .24 & .36 & .36 \\
\hline US & .94 & .24 & .16 & .36 & .08 & .24 & .00 & .00 & .30 & .21 \\
\hline Total & .89 & .31 & .29 & .45 & .08 & .26 & .03 & .16 & .32 & .29 \\
\hline \multicolumn{11}{|l|}{ See } \\
\hline Ngöbe & 1 & .00 & .26 & .41 & .04 & .21 & .04 & .21 & .34 & .21 \\
\hline US & .91 & .21 & .01 & .06 & .05 & .19 & .00 & .00 & .24 & .11 \\
\hline Total & .95 & .17 & .11 & .29 & .05 & .20 & .02 & .13 & .28 & .20 \\
\hline Kind Total & .95 & .13 & .43 & .37 & .14 & .27 & .06 & .16 & .39 & .23 \\
\hline \multicolumn{9}{|c|}{ Overall psychological attributions (composite scores averaged across 5 capacities) } & \multicolumn{2}{|c|}{ Total } \\
\hline Ngöbe & .95 & .08 & .61 & .33 & .19 & .25 & .12 & .22 & .47 & .18 \\
\hline US & .96 & .07 & .26 & .20 & .08 & .18 & .01 & .02 & .33 & .08 \\
\hline Total & .96 & .08 & .40 & .31 & .13 & .22 & .05 & .15 & .39 & .15 \\
\hline
\end{tabular}


Table A2: Table of effects for Exp. 1B: Culture, kind, and capacity attributions

\begin{tabular}{|c|c|c|}
\hline$\underline{\text { Effect }}$ & $F$ test & Post-hoc \\
\hline Culture & $\begin{array}{l}F(1,54)=15.26^{* * *} \\
\eta^{2}=.22\end{array}$ & Ngöbe $(M=.47)>$ US $(M=.33)$ \\
\hline Kind & $\begin{array}{l}(3,162)=388.53^{* * *} \\
\eta^{2}=.88\end{array}$ & $\begin{array}{l}\text { Animals }(M=.95)>\text { Plants }(M=.43)>\text { Machines }(M=.14)>\text { Artifacts } \\
(M=.06)\end{array}$ \\
\hline Capacity attribution & $\begin{array}{l}F(4,216)=40.78^{* * *} \\
\eta^{2}=.43\end{array}$ & $\begin{array}{l}(\text { Feel, Want }>\text { Pain, Think, See })(\text { Pain }>\text { See }) \\
\text { Feel }(M=.52) \text {, Want }(M=.45) \text {, Pain }(M=.36) \text {, Think }(M=.32) \text {, See }(M= \\
.28)\end{array}$ \\
\hline Culture $\square$ Kind & $\begin{array}{l}F(3,162)=13.09^{* * *} \\
\eta^{2}=.20\end{array}$ & $\begin{array}{l}\text { Plants: Ngöbe }(M=.61)>\text { US }(M=.26) \\
\text { Artifacts: Ngöbe }(M=.12)>\text { US }(M=.02)\end{array}$ \\
\hline Culture $\times$ Capacity & $\begin{array}{l}F(4,216)=4.36^{*} \\
\eta^{2}=.08\end{array}$ & $\begin{array}{l}\text { Feel: Ngöbe }(M=.59)>\text { US }(M=.46) \\
\text { Want: Ngöbe }(M=.56)>\text { US }(M=.36) \\
\text { Pain: Ngöbe }(M=.49)>\text { US }(M=.27) \\
\text { See: Ngöbe }(M=.34)>\text { US }(M=.24)\end{array}$ \\
\hline Kind $\times$ Capacity & $\begin{array}{l}F(12,648)=16.04^{* * *} \\
\eta^{2}=.23\end{array}$ & $\begin{array}{l}\text { Animals > All other kinds: for all } 5 \text { capacities } \\
\text { Plants > Machines, Artifacts: for } 4 \text { capacities (not See) } \\
\text { Machines > Artifacts: for Want }\end{array}$ \\
\hline $\begin{array}{l}\text { Culture } \times \text { Kind } \times \\
\text { Capacity } \\
\text { Animals: }\end{array}$ & $\begin{array}{l}F(12,648)=4.59^{* * *} \\
\eta^{2}=.08\end{array}$ & (see separate tests for each kind below) \\
\hline Culture $\times$ Capacity & $\begin{array}{l}F(4,216)=2.96^{*} \\
\eta^{2}=.05\end{array}$ & See: Ngöbe $(M=1)>$ US $(M=.91)$ \\
\hline \multicolumn{3}{|l|}{ Plants: } \\
\hline Culture $\times$ Capacity & $\begin{array}{l}F(4,216)=5.57^{* *} \\
\eta^{2}=.09\end{array}$ & $\begin{array}{l}\text { Feel: Ngöbe }(M=.84)>\text { US }(M=.69) \\
\text { Want: Ngöbe }(M=.78)>\text { US }(M=.37) \\
\text { Pain: Ngöbe }(M=.71)>\text { US }(M=.08) \\
\text { See: Ngöbe }(M=.26)>\text { US }(M=.01)\end{array}$ \\
\hline \multicolumn{3}{|l|}{ Machines: } \\
\hline Culture $\times$ Capacity & $\begin{array}{l}F(4,216)=3.40^{*} \\
\eta^{2}=.06\end{array}$ & $\begin{array}{l}\text { Want: Ngöbe }(M=.35)>\text { US }(M=.13) \\
\text { Pain: Ngöbe }(M=.16)>\text { US }(M=.00)\end{array}$ \\
\hline Artifacts: & & \\
\hline Culture $\times$ Capacity & $\begin{array}{l}F(4,216)=4.97^{* *} \\
\eta^{2}=.08\end{array}$ & $\begin{array}{l}\text { Feel: Ngöbe }(M=.23)>\mathrm{US}(M=.02) \\
\text { Want: Ngöbe }(M=.13)>\mathrm{US}(M=.01)\end{array}$ \\
\hline
\end{tabular}

\section{Appendix B: Language}

\section{B1. Language protocol}

1138 Primary probes were always presented in the assigned interview language but participants were

1139 free to respond in their preferred language; nearly all responded in the assigned interview

1140 language (including the US text-based responses, and Panama verbal responses). 


\section{B2. Supplementary language results}

1142 Among US participants, there were no reliable effects of Spanish versus English for any of the

1143 experiments. Among Ngöbe participants, no language effects were observed for Spanish versus

1144 Ngöbere on the capacity attribution tasks (Experiments 1B and 2B), where any cross-linguistic

1145 differences could have been relevant as an alternative account of observed cultural differences.

1146 Unexpectedly, Spanish-Ngöbere language differences were found among Ngöbe participants for

1147 the goal-directed action prediction task (Experiment 1A). Participants predicted more goal-

1148 directed actions for plants (across both BA and BP conditions) and animals in Ngöbere than

1149 Spanish (Plants: $F(1,19)=6.46, p<.05, \eta^{2}=.25$; Ngöbere $M=.72, S D=.28$; Spanish $M=.44, S D=$

$1150.40)\left(\right.$ Animals: $(1,19)=4.67, p<.05, \eta^{2}=.20$, Ngöbere $M=.97, S D=.10$; Spanish $\left.M=.73, S D=.42\right)$.

1151 Predictions for machines and artifacts did not differ. This is the one study where we did not

1152 predict (or find) cultural differences between US and Ngöbe samples, so the observed language

1153 effects are incidental to our primary cultural hypotheses. In any case, they do not alter the overall

1154 findings reported for Experiment 1A. We do not think this indicates that Spanish instructions

1155 were unclear to participants, because action predictions did not differ for machines or artifacts by

1156 language.

1157 The observed effects of language may point to other factors. Both language and stimulus version

1158 were correlated with demographic characteristics in our sample: participants in the Ngöbere

1159 condition tended to be older and to have fewer years of formal schooling, while participants in

1160 the familiar plant stimulus version had less schooling (correlated with stimulus version $r=-.62, p$

$1161<.01)$ and were more likely to be members of the Indigenous Ngöbe Church $(r=.59, p<.01)$. The

1162 multiply correlated factors in our sample make it difficult to isolate a single factor in explaining

1163 the observed differences for predictions of plant goal-directed actions. 


\section{Appendix C: Experiment 2}

\section{C1. Participants, pilots and protocol development}

1166 Development of the action prediction scenarios and capacity questions involved piloting with

1167 several participants. Additionally, some participants did not complete the interview, either

1168 leaving blank survey responses (in the US) or finishing early to avoid exhaustion in longer

1169 interviews (in Panama). Altogether including pilots, 22 Ngöbe and 32 US individuals participated

1170 in Experiments 2A and 2B. Given that many items that pilot participants saw were nearly

1171 identical to the final items, we also conducted all analyses reported here on the full participant

1172 sample including pilots. All findings hold across both sample sets.

1173 C2. Experiment 2A: Supplementary methods and materials

1174 Communication scenarios

1175

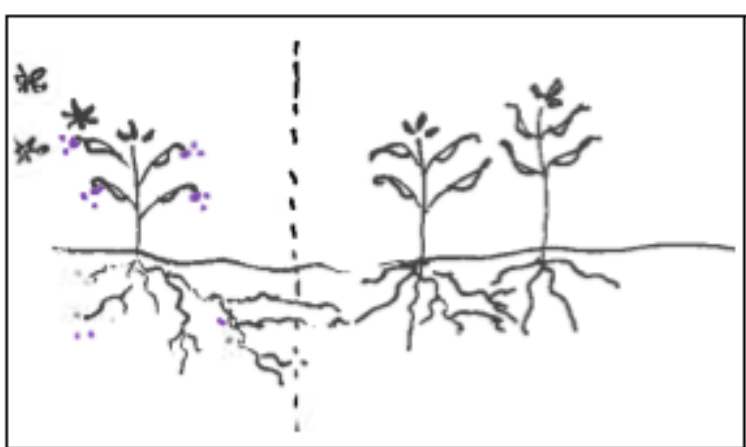

Insect scenario

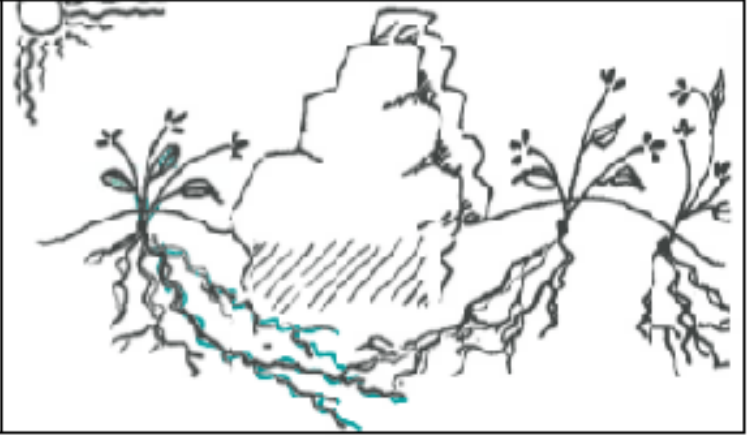

Drought scenario

(i) Insect communication scenario

1178 Here are 3 plants of the same species. There is an above-ground wall separating the plant on the

1179 left from the two plants on the right. The leaves of the individual plants can't touch each other,

1180 but the roots are connected. Some insects have arrived and are irritating the plant on the left. As a 1181 result, the plant has released chemicals to defend itself from the insects. The chemical is released 
1182 through both the leaves and the roots. What will happen to the two plants on the other side of the

1183 wall, after the left plant releases defensive chemicals against the insects? (Assume that the insects

1184 have not arrived on the right side of the wall yet.) (1) The other two plants will also release their

1185 chemicals to defend themselves. (2) The other two plants will remain in the same state as before,

1186 without releasing chemicals.

1187 Aquí hay 3 plantas de la misma especie. Hay una pared encima del suelo separando la planta a la izquierda

1188 de las otras dos plantas a la derecha. Las hojas de las plantas individuales no pueden tocarse las unas con

1189 las otras, pero las raíces si están conectadas. Han llegado unos insectos a molestar la planta a la izquierda.

1190 A consecuencia, la planta ha echado unos químicos para defenderse de los insectos. Los químicos son

1191 descargados por medio de las hojas y las raíces. ¿Qué va a pasar con las dos plantas al otro lado de la pared

1192 después que la planta a la izquierda echo químicos defensivos contra los insectos? (Asume que los insectos

1193 todavía no han llegado al lado derecho de la pared.) (1) Las otras 2 plantas van a echar el químico para

1194 defenderse de los insectos también. (2) Las otras 2 plantas se van a quedar igual como siempre, sin echar

1195 químicos.

1196 (ii) Drought communication scenario

1197 Here are three plants of the same species. These plants have long roots that extend to great

1198 depths because they live in an arid area where water is located deep underground. There is one

1199 plant growing by itself on the left side of a huge rock cliff. It is connected to the middle plant via

1200 roots that travel beneath the rock, but it is not connected to the third plant on the far right. The

1201 climate on the left side of the cliff is a bit different from the climate on the right side. Currently,

1202 there is a severe drought on the left side. In order to defend itself from the drought, the left plant

1203 undergoes a change in its body that allows it to conserve its water use. The drought has not yet

1204 reached the other side of the cliff, but it will arrive there in three weeks with even more intensity. 
1205 What will happen to the other two plants when the drought arrives on the right side of the cliff?

1206 (1) They are both going to die because neither of them were prepared beforehand. (2) Only the

1207 plant that was connected will survive because it was prepared beforehand.

1208 Aqui hay tres plantas de la misma especie. Estas plantas tienen raíces muy largas que alcanzan una

1209 profundidad porque viven en un área seca donde el agua está profundamente debajo del suelo. Hay una

1210 planta que está creciendo sola al lado izquierdo de una roca grande. Esta planta está conectada a la planta

1211 en medio por medio de las raíces que recorren debajo de la roca, pero no está conectada a la tercera planta

1212 que está a la derecha. El clima a la izquierda de la roca es un poco diferente del clima al lado derecho de la

1213 roca. Ahorita, hay una sequía grande al lado izquierdo. Para defenderse de la sequía, la planta a la izquierda

1214 hace un cambio en su cuerpo que la permite conservar su uso de agua. La sequía todavía no ha alcanzado el

1215 lado derecho de la roca, pero va a llegar en tres semanas con más intensidad. ¿Qué va a pasar con las otras

1216 dos planta cuando llegue la sequía al lado derecho de la roca? Que pasara cuando la sequía llegue donde

1217 ellas? (1) Ellas dos van a morir porque ninguna de ellas estaban preparadas. (2) Solo la planta que estaba

1218 conectada va a sobrevivir porque ella estaba preparada antes.

1219 Kin Altruism Scenarios

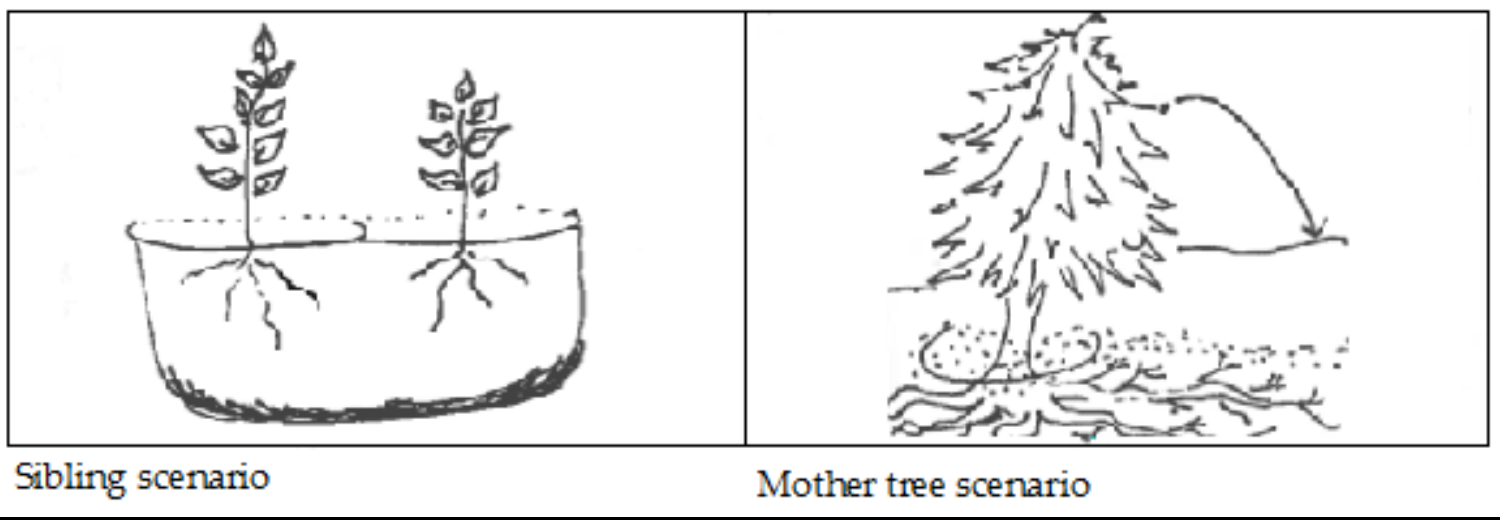


1222 The two plants in this pot are of the same species, but are unrelated (not biological kin). If one of

1223 the plants is stronger than the other and can more quickly extend its roots, it will capture all the

1224 nutrients until the other plant dies. This frequently occurs among unrelated plants. Now we have

1225 two plants that are related: they are biological kin. One of the plants (on the left) is stronger than

1226 the other and can extend its roots faster than its sibling (on the right). What will happen in this

1227 case with the two plants that are biological kin? (1) The stronger plant will extend its roots in all

1228 directions and take all the nutrients until its sibling dies. (2) The stronger plant will share the

1229 nutrients with its sibling and both will survive.

1230 Estas dos plantas en la maceta son de la misma especie, pero no están relacionadas (no son descendentes de

1231 la misma planta). Si una de las plantas es más fuerte que la otra y puede crecer sus raíces en todas partes

1232 más rápidamente, puede capturar todos los nutrientes hasta que la otra planta se muera. Esto pasa con

1233 frecuencia entre plantas que no son relacionadas. Ahora tenemos dos plantas que son relacionadas: son

1234 descendentes de la misma planta. Una de las planta (a la izquierda) es más fuerte que la otra y puede

1235 extender sus raíces más rápido que su hermano (a la derecha). ¿Que pasara en este caso con las dos plantas

1236 que son descendentes de la misma planta? (1) La planta más fuerte va a crecer sus raíces en todas

1237 direcciones y capturar todos los nutrientes hasta que su hermano muera. (2) La planta más fuerte va a

1238 compartir los nutrientes con su hermano y los dos van a sobrevivir.

1239 (iv) Mother tree kin altruism scenario

1240 Here is a large tree that is growing in the mountains. After reproducing, it releases one of its

1241 seeds. Where will the seed grow better? (Suppose that there is the same amount of sunlight and

1242 nutrients in both locations.) (1) Near its mother's roots. (2) Farther away where there are no roots 1243 from its mother. 
1244 Aquí hay un árbol grande que está creciendo en la montaña. Después de haber reproducido, el árbol

1245 descargo una de sus semillas. Dónde va crecer mejor la semilla? (Supone que hay la misma cantidad de luz

1246 del sol y nutrientes en las dos posiciones.) (1) Cerca de las raíces de la mama. (2) Más lejos donde no hay

1247 raíces de la mama.

1248 C3. Supplementary results on plant interaction predictions

Plant communication: Separate analyses of each prediction scenario showed that this

1250 cultural difference held for both communication in response to insects (Ngöbe $M=.94, S D=.24$;

$1251 \mathrm{US} M=.70, S D=.47), \mathrm{t}(44.80)=2.33, p<.05, \mathrm{~d}=0.70$, and communication in response to drought

1252 (Ngöbe $M=.94, S D=.25 ; \mathrm{US} M=.70, S D=.47), \mathrm{t}(43.98)=2.25, p<.05, \mathrm{~d}=0.68$. Kin altruism:

1253 Separate analyses of each prediction item showed that Ngöbe were far more likely to predict

1254 sibling resource sharing $(M=.82, S D=.39)$ than US participants $(M=.30, S D=.47), \mathrm{t}(45)=3.91, p$

$1255<.001, \mathrm{~d}=1.16$, but there was no difference in predictions for mother tree, $\mathrm{t}(43)=-0.03, p=.98$

1256 (Ngöbe $M=.35, S D=.49 ;$ US $M=.36$, $S D=.49$ ).

1257 
1259 Table C1: Coding categories for explanations of plant social action predictions

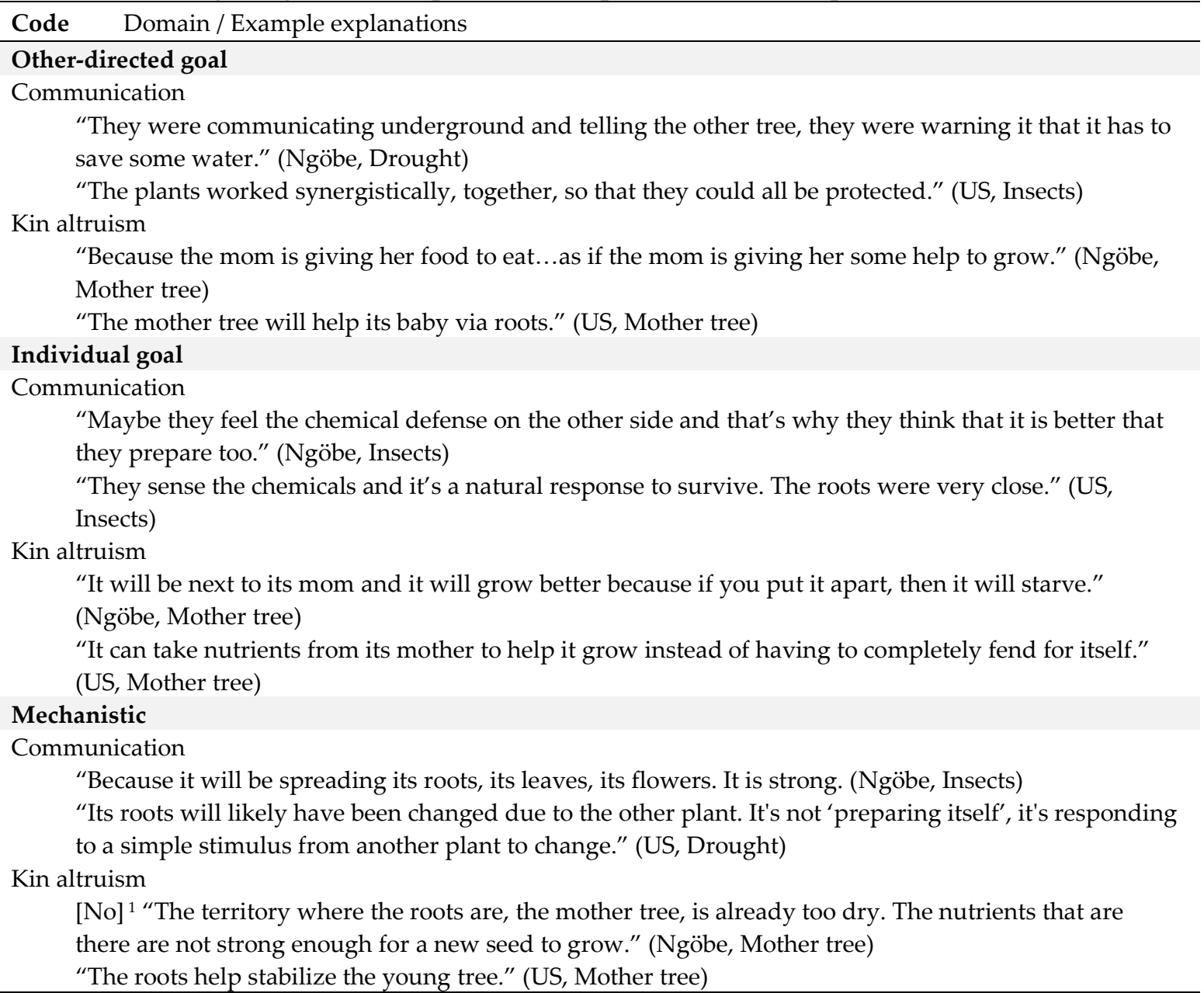

${ }^{1}$ All explanations are for positive action predictions, except this case where none was available because no Ngöbe respondent provided a mechanistic explanation for kin altruism. 
1261 Coding reliability. Two independent coders judged a subset of explanations (representing over $30 \%$ of the corpus of explanations) for interpretations of plant interactions. Inter-rater reliability

1263 on the assignment of explanatory codes was high for both communication explanations (Kappa=

$1264.81, p<.001$; percent agreement $=88 \%)$ and kin altruism explanations $($ Kappa $=.76, p<.001$;

1265 percent agreement $=88 \%$ ).

1266 Detailed coding results. Kin altruism: Explanation data was available from US participants for the

1267 mother tree scenario but not the sibling plant scenario, so we do not report coding analyses for

1268 kin altruism explanations in the main text. Nonetheless, the results from available explanation

1269 data roundly supported our overall thesis, as reported here. Mother tree. Among participants who

1270 predicted that the seedling would grow better closer to its mother $(N=16)$, we found that only

1271 Ngöbe construed the interaction as one involving the mother's goals for her seedling, as indicated

1272 by a reliable cultural difference on the $2 \times 3$ chi-square analysis, $\chi^{2}(1, N=16)=5.88$, exact, 2 -sided

$1273 p<.05$ (using the N-1 chi-square test). Ngöbe were more likely to refer to social goals than either

1274 individual goals or biological mechanisms. In contrast, US participants predominantly explained

1275 the mother-tree interaction in terms of biological mechanisms or individual goals. Sibling plants:

1276 Ngöbe explanations for sibling sharing were analyzed, and these showed the same pattern of

1277 social goal interpretations as for the other prediction scenarios.

1278 C5. Experiment 2B: Supplementary methods and materials

1279 Question probes for social capacity attributions as translated into each study language (English,

1280 Spanish) are provided below, with accompanying stimuli indicated in brackets.

1281 Signaling. Do you think that plants can communicate with and send signals to one

$1282 \quad$ another?

$1283 \quad$ ¿Tú crees que las plantas pueden comunicar o mandar señales entre ellas mismas? 
[Insect communication illustration]

Kin recognition. Do you think that plants can recognize who their kin are? ¿Tú crees que las plantas pueden reconocer quiénes son sus descendentes? [Sibling plant illustration]

Mother help. Do you think that a mother tree can help its baby tree via roots? ¿Crees que la mama puede ayudar él bebe árbol por medio de sus raíces?

[Mother tree illustration] caído. ¿Ellos pueden sentir el dolor del árbol, aunque ellos mismos no fueron cortados? [Photograph of a chainsaw-fallen tree and stump]

1303 In addition to the cultural differences reported in the main text, there were several main effects 1304 and interactions, as would be expected (evident in Figure 5 presented in the main text). Main 1305 effects: There was a main effect of capacity, $F(3,126)=8.43, p<.001, \eta^{2}=.17$. Plant signaling was 1306 most often endorsed $(M=.81, S D=.44)$ and reliably more so than either feel other's pain $(M=.41$, $1307 S D=.31)$ or kin recognition $(M=.56, S D=.50), \mathrm{ps}<.05$. The capacity for a mother to help 
1308 offspring $(M=.66, S D=.50)$ was more often endorsed than feel other's pain, $p<.05$. Capacity 1309 attributions for feel other's pain and kin recognition did not reliably differ.

1310 


\section{References}

Abramson, C. I., \& Chicas-Mosier, A. M. (2016). Learning in plants: lessons from Mimosa pudica. Frontiers in psychology, 7.

Alpi, A., Amrhein, N., Bertl, A., Blatt, M. R., Blumwald, E., Cervone, F., . . Galston, A. W. (2007). Plant neurobiology: no brain, no gain? Trends in plant science, 12(4), 135-136.

Anders, R. (2013). CCTpack: Cultural Consensus Theory applications to data. R package version 1.2.

Anders, R. (2014). Package "CCTpack" Manual. Retrieved from http://citeseerx.ist.psu.edu/viewdoc/download?doi=10.1.1.649.4064\&rep=rep1\&type=pdf

Anders, R., Oravecz, Z., \& Batchelder, W. H. (2014). Cultural consensus theory for continuous responses: a latent appraisal model for information pooling. Journal of Mathematical Psychology, 61, 1-13.

Anderson, E. N. (1996). Ecologies of the Heart: Oxford University Press New York.

Anderson, E. N. (2005). Political ecology in a Yucatec Maya community: University of Arizona Press.

Anderson, E. N. (2012). Religion in conservation and management: A Durkheimian view. Journal for the Study of Religion, Nature and Culture, 6(4), 398-420.

Atran, S., \& Medin, D. L. (2008). The native mind and the cultural construction of nature: MIT Press Cambridge.

Atran, S., Medin, D. L., \& Ross, N. O. (2005). The cultural mind: environmental decision making and cultural modeling within and across populations. Psychological Review, 112(4), 744.

Atran, S., \& Norenzayan, A. (2004). Religion's evolutionary landscape: Counterintuition, commitment, compassion, communion. Behavioral and brain sciences, 27(06), 713-730.

Bang, M., Medin, D. L., \& Atran, S. (2007). Cultural mosaics and mental models of nature. Proceedings of the National Academy of Sciences, 104(35), 13868-13874.

Barrett, J. L. (2000). Exploring the natural foundations of religion. Trends in Cognitive Sciences, 4(1), 29-34.

Bhatt, M. V., Khandelwal, A., \& Dudley, S. A. (2011). Kin recognition, not competitive interactions, predicts root allocation in young Cakile edentula seedling pairs. New Phytologist, 189(4), 1135-1142.

Biedrzycki, M. L., \& Bais, H. P. (2010). Kin recognition in plants: a mysterious behaviour unsolved. Journal of experimental botany, erq250.

Bird-David, N. (1999). “Animism” Revisited: Personhood, Environment, and Relational Epistemology 1. Current Anthropology, 40(S1), S67-S91.

Bíró, S., \& Leslie, A. M. (2007). Infants' perception of goal-directed actions: development through cue-based bootstrapping. Developmental science, 10(3), 379-398.

Boyer, P. (1996). What makes anthropomorphism natural: Intuitive ontology and cultural representations. Journal of the Royal Anthropological Institute, 83-97.

Boyer, P. (2003). Religious thought and behaviour as by-products of brain function. Trends in Cognitive Sciences, 7(3), 119-124.

Brenner, E. D., Stahlberg, R., Mancuso, S., Vivanco, J., Baluška, F., \& Van Volkenburgh, E. (2006). Plant neurobiology: an integrated view of plant signaling. Trends in plant science, 11(8), 413-419.

Cajete, G. (2000). Native science: Natural laws of interdependence: Clear Light Books Santa Fe, NM.

Campbell, I. (2007). Chi-squared and Fisher-Irwin tests of two-by-two tables with small sample recommendations. Statistics in Medicine, 26(19), 3661-3675.

Carey, S. (1985). Conceptual change in childhood. Cambridge, MA: Bradford Books.

Carey, S. (2009). The origin of concepts. Oxford, UK: Oxford University Press.

Chamovitz, D. (2012). What a plant knows: a field guide to the senses: Macmillan. 
Csibra, G., \& Gergely, G. (2013). Teleological understanding of actions. In M. R. Banaji \& S. A. Gelman (Eds.), Navigating the social world (pp. 38-43). New York: Oxford University Press.

Csibra, G., Gergely, G., Bíró, S., Koos, O., \& Brockbank, M. (1999). Goal attribution without agency cues: the perception of 'pure reason'in infancy. Cognition, 72(3), 237-267.

Cvrčková, F., Žárský, V., \& Markoš, A. (2016). Plant studies may lead us to rethink the concept of behavior. Frontiers in psychology, 7.

Danziger, E. (2006). The thought that counts: Interactional consequences of variation in cultural theories of meaning. In N. J. Enfield \& S. C. Levinson (Eds.), Roots of human sociality: Culture, Cognition and Interaction (pp. 259-278). Oxford, UK: Berg.

Danziger, E. (2010). On trying and lying: Cultural configurations of Grice's Maxim of Quality. Intercultural Pragmatics, 7(2), 199-219.

Danziger, E., \& Rumsey, A. (2013). Introduction: From Opacity to intersubjectivity across languages and cultures. Language and Communication, 33(3), 247-250.

Dennett, D. C., \& Haugeland, J. (1987). Intentionality. The Oxford companion to the mind.

Descola, P. (1996). Constructing natures. Nature and society: anthropological perspectives, 82-102.

Dudley, S. A., \& File, A. L. (2007). Kin recognition in an annual plant. Biology Letters, 3, 435-438.

Duranti, A. (1988). Intentions, language, and social action in a Samoan context. Journal of Pragmatics, 12(1), 13-33.

Duranti, A. (2008). Further reflections on reading other minds. Anthropological Quarterly, 81(2), 483-494.

Erickson, J. E., Keil, F. C., \& Lockhart, K. L. (2010). Sensing the coherence of biology in contrast to psychology: Young children's use of causal relations to distinguish two foundational domains. Child development, 81(1), 390-409.

Falik, O., Mordoch, Y., Quansah, L., Fait, A., \& Novoplansky, A. (2011). Rumor has it...: relay communication of stress cues in plants. PLoS One, 6(11), e23625.

Fausey, C. M., \& Boroditsky, L. (2011). Who dunnit? Cross-linguistic differences in eye-witness memory. Psychonomic bulletin \& review, 18(1), 150-157.

Fausey, C. M., Long, B. L., Inamori, A., \& Boroditsky, L. (2010). Constructing agency: the role of language. Frontiers in psychology, 1.

FORMABIAP. (2008). La vida secreta de las plantas medicinales en los pueblos kichwa, kukamakukamiria y tikuna. In P. d. f. d. m. b. d. 1. A. peruana (Ed.), Una aproximacion al concocimiento de algunas plantas de uso medicinal en la comunidad educativa de Zungarococha (pp. 228). Iquitos: Serie: Construyendo interculturalidad.

Gelman, S. A. (2009). Learning from others: Children's construction of concepts. Annual review of psychology, 60, 115-140.

Gergely, G., \& Csibra, G. (2003). Teleological reasoning in infancy: The navve theory of rational action. Trends in cognitive sciences, 7(7), 287-292.

Goddard, C. (2003). Thinking across languages and cultures: Six dimensions of variation. Cognitive Linguistics, 14(2/3), 109-140.

Goddard, C. (2010). Universals and variation in the lexicon of mental state concepts. In B. C. Malt \& P. Wolff (Eds.), Words and the Mind: How Words Capture Human Experience (pp. 72-93). New York: Oxford University Press.

Gordon, B. L. (1982). A Panama forest and shore: natural history and Amerindian culture in Bocas del Toro: Pacific Grove: California, Boxwood Press.

Gutheil, G., Vera, A., \& Keil, F. C. (1998). Do houseflies think? Patterns of induction and biological beliefs in development. Cognition, 66(1), 33-49. 
1405

1406

1407

1408

1409

1410

1411

1412

1413

1414

1415

1416

1417

1418

1419

1420

1421

1422

1423

1424

1425

1426

1427

1428

1429

1430

1431

1432

1433

1434

1435

1436

1437

1438

1439

1440

1441

1442

1443

1444

1445

1446

1447

1448

1449

1450

1451

Guthrie, S., Agassi, J., Andriolo, K. R., Buchdahl, D., Earhart, H. B., Greenberg, M., . . Sharpe, K. J. (1980). A Cognitive Theory of Religion [and Comments and Reply]. Current Anthropology, 181-203.

Hall, M. (2011). Suny Series on Religion and the Environment: Plants As Persons: a Philosophical Botany: SUNY Press.

Hallowell, A. I. (1960). Ojibwa ontology, behavior, and world view Readings in indigenous religions (pp. 18-49).

Harvey, G. (2005). Animism: Respecting the living world. Kent Town, South Australia: Wakefield Press.

Hatano, G., \& Inagaki, K. (1994). Young children's naive theory of biology. Cognition, 50(1), 171188.

Heidelberger, M. (2004). Nature from within: Gustav Theodor Fechner and his psychophysical worldview: University of Pittsburgh Press.

Heil, M., \& Karban, R. (2010). Explaining evolution of plant communication by airborne signals. Trends in Ecology \& Evolution, 25(3), 137-144.

Herrmann, P., Waxman, S. R., \& Medin, D. L. (2010). Anthropocentrism is not the first step in children's reasoning about the natural world. Proceedings of the National Academy of Sciences, 107(22), 9979-9984.

Hirschfeld, L. A. (2006). Who needs a theory of mind? In R. Viale, D. Andler \& L. A. Hirschfeld (Eds.), Biological and cultural bases of human inference (pp. 131-160). Mahwah, NJ: Lawrence Erlbaum Publishers.

Hirschfeld, L. A. (2013). The myth of mentalizing and the primacy of folk sociology. In M. Banaji \& S. A. Gelman (Eds.), Navigating the Social World: What Infants, Children, and Other Species Can Teach Us (pp. 101-106). Oxford, UK: Oxford University Press.

Hirschfeld, L. A., \& Gelman, S. A. (1994). Mapping the mind: Domain specificity in cognition and culture: Cambridge University Press.

Inagaki, K., \& Hatano, G. (2004). Vitalistic causality in young children's naive biology. Trends in cognitive sciences, 8(8), 356-362.

Ingold, T. (2006). Rethinking the animate, re-animating thought. Ethnos, 71(1), 9-20.

Ingold, T. (2010). The man in the machine and the self-builder. Interdisciplinary Science Reviews, 35(3-4), 353-364.

Ingold, T. (2011). Being alive: Essays on movement, knowledge and description: Taylor \& Francis.

Johannessen, C. L. (1970). The dispersal of Musa in Central America: the domestication process in action. Annals of the Association of American Geographers, 60(4), 689-698.

Johnson, H. M. (1945). Are Psychophysical Problems Genuine or Spurious? The American Journal of Psychology, 58(2), 189-211.

Johnson, S. C. (2000). The recognition of mentalistic agents in infancy. Trends in Cognitive Sciences, $4(1), 22-28$.

Johnson, S. C. (2003). Detecting agents. Philosophical Transactions of the Royal Society of London. Series B: Biological Sciences, 358(1431), 549-559.

Johnson, S. C., Shimizu, Y., \& Ok, S.-J. (2007). Actors and actions: The role of agent behavior in infants' attribution of goals. Cognitive Development, 22(3), 310-322.

Keil, F. C. (1995). The growth of causal understandings of natural kinds: modes of construal and the emergence of biological thought. In D. Sperber, Premack, D., \& Premack, A. J. (Ed.), Causal cognition: A multidisciplinary debate. (pp. 234-267). Oxford, UK: Clarendon Press.

Kelemen, D. (2003). British and American children's preferences for teleo-functional explanations of the natural world. Cognition, 88(2), 201-221. 
1452

1453

1454

1455

1456

1457

1458

1459

1460

1461

1462

1463

1464

1465

1466

1467

1468

1469

1470

1471

1472

1473

1474

1475

1476

1477

1478

1479

1480

1481

1482

1483

1484

1485

1486

1487

1488

1489

1490

1491

1492

1493

1494

1495

1496

1497

1498
Keller, E. F. (1983). A feeling for the organism: The life and work of Barbara McClintock. New York: WH Freeman and Company.

Kimmerer, R. W. (2013). Braiding sweetgrass: indigenous wisdom, scientific knowledge and the teachings of plants. Minneapolis, MN: Milkweed Editions.

Klemens, J. A. (2008). Kin recognition in plants? Biology Letters, 4(1), 67-68.

Kohn, E. (2007). How dogs dream: Amazonian natures and the politics of transspecies engagement. American ethnologist, 34(1), 3-24.

Kohn, E. (2013). How Forests Think: Toward an Anthropology beyond the Human: Univ of California Press.

Kohn, E. (2015). Anthropology of ontologies. Annual Review of Anthropology, 44, 311-327.

Kopesec, M. (1975). Los elementos verbales y sustantivos y la oración en guaymí. Lenguas de Panamá, 2, 19-82.

Le Guen, O., Iliev, R., Lois, X., Atran, S., \& Medin, D. L. (2013). A garden experiment revisited: inter-generational change in environmental perception and management of the Maya Lowlands, Guatemala. Journal of the Royal Anthropological Institute, 19(4), 771-794.

Lewis, M. P. (Ed.). (2009). Ethnologue: Languages of the World (16th ed.). Dallas, TX: SIL International.

Lillard, A. (1998). Ethnopsychologies: cultural variations in theories of mind. Psychological bulletin, 123, 3-32.

Lima, T. S. (1999). The two and its many: Reflections on perspectivism in a Tupi cosmology. Ethnos, 64(1), 107-131.

Lindsay, W. L. (1876). Mind in plants. The British Journal of Psychiatry, 21(96), 513-532.

Lowder, M. W., \& Gordon, P. C. (2015). Natural forces as agents: Reconceptualizing the animateinanimate distinction. Cognition, 136, 85-90.

Luhrmann, T. (2011). Toward an anthropological theory of mind (Overview). Suomen Antropol. J. Finn. Anthropol. Soc, 36, 5-69.

Mancuso, S., \& Viola, A. (2015). Brilliant Green: The Surprising History and Science of Plant Intelligence: Island Press.

Marder, M. (2012). Plant intentionality and the phenomenological framework of plant intelligence. Plant signaling \& behavior, 7(11), 1365-1372.

Marder, M. (2013). Plant intelligence and attention. Plant Signaling \& Behavior, 8(5), e23902. doi: 10.4161/psb.23902

Medin, D. L., \& Bang, M. (2014). Who's asking? Native Science, Western Science and Science Education. Cambridge, MA: MIT Press.

Medin, D. L., ojalehto, b., Waxman, S. R., \& Bang, M. (2015). Relations: language, epistemologies, categories and concepts. In E. Margolis \& S. Laurence (Eds.), The Conceptual Mind: New Directions in the Study of Concepts. Cambridge, MA: MIT Press.

Medin, D. L., Ross, N., Cox, D., \& Atran, S. (2007). Why folkbiology matters: Resource conflict despite shared goals and knowledge. Human Ecology, 35(3), 315-329.

Meltzoff, A. N., \& Gopnik, A. (2013). Learning about the mind from evidence: Children's development of intuitive theories of perception and personality. In S. Baron-Cohen, H. Tager-Flausber \& M. Lombardo (Eds.), Understanding Other Minds (3rd ed., pp. 19-34). Oxford, England: Oxford University Press.

Montezuma, L. P. (1991). Nun Roae Kugwe Kira Niebare Nuen: Nuestros Abuelos Nos Contaron Historias (Our Grandparents Told Us These Stories). Comarca Ngobe, Panama: Accion Cultural Ngobe.

Narby, J. (2006). Intelligence in nature: An inquiry into knowledge: Penguin. com. 
ojalehto, b., Medin, D., \& Garcia, S. (2015). Agency concepts across cultures: How intuitive is folkpsychology? Paper presented at the 37th Annual Meeting of the Cognitive Science Society, Pasadena, CA.

ojalehto, b., Medin, D., \& Garcia, S. (submitted). Grounding principles for inferring agency: Two cultural perspectives.

ojalehto, b., Medin, D., Horton, W., Garcia, S., \& Kays, E. (2015). Seeing cooperation or competition: Ecological interactions in cultural perspectives. Topics in Cognitive Science(Anthropological perspectives on cognition), 1-22. doi: 10.1111/tops.12156 ojalehto, b., \& Medin, D. L. (2015). Perspectives on culture and concepts. Annual Review of Psychology, 66, 249-275. doi: 10.1146/annurev-psych-010814-015120

ojalehto, b., Waxman, S. R., \& Medin, D. L. (2013). Teleological reasoning about nature: intentional design or relational perspectives? Trends in Cognitive Sciences, 17(4), 166-171.

Opfer, J. E. (2002). Identifying living and sentient kinds from dynamic information: The case of goal-directed versus aimless autonomous movement in conceptual change. Cognition, 86(2), 97-122.

Opfer, J. E., \& Gelman, S. A. (2001). Children's and Adults' Models for Predicting Teleological Action: The Development of a Biology-Based Model. Child development, 72(5), 1367-1381.

Opfer, J. E., \& Siegler, R. S. (2004). Revisiting preschoolers' "living things" concept: A microgenetic analysis of conceptual change in basic biology. Cognitive psychology, 49(4), 301-332.

Pierotti, R. (2011). Indigenous knowledge, ecology, and evolutionary biology. New York: Routledge: Taylor \& Francis Group.

Pitman, N. C., Cecilio, M. P., Pudicho, M. P., Graham, J. G., Núñez V, M. P., Valenzuela, M., \& Terborgh, J. W. (2011). Indigenous perceptions of tree species abundance across an upper Amazonian landscape. Journal of Ethnobiology, 31(2), 233-243.

Ramos, A. R. (2012). The politics of perspectivism. Annual Review of Anthropology, 41, 481-494.

Rappaport, R. A. (1979). Ecology, meaning, and religion: North Atlantic Books Richmond, CA.

Reichel-Dolmatoff, G. (1976). Cosmology as ecological analysis: A view from the rain forest. Man, 307-318.

Reid, A. (1994). Diccionario Guaymi-Espanol-Ingles Diccionario Guaymi-Espanol-Ingles. Panama: Asamblea Espiritual Nacional de los Baha'is de Panama.

Robbins, J., \& Rumsey, A. (2008). Introduction: Cultural and linguistic anthropology and the opacity of other minds. Anthropological Quarterly, 81(2), 407-420.

Romney, A. K., Weller, S. C., \& Batchelder, W. H. (1986). Culture as consensus: A theory of culture and informant accuracy. American anthropologist, 88(2), 313-338.

Ross, N., Medin, D., Coley, J. D., \& Atran, S. (2003). Cultural and experiential differences in the development of folkbiological induction. Cognitive Development, 18(1), 25-47.

Santos-Granero, F. (2009). The occult life of things: Native Amazonian theories of materiality and personhood: University of Arizona Press.

Santos-Granero, F. (2012). "Here No Poop": The Dangers and Prospects of Intersubjective Relations in Amerindian Political Economies of Life. Anthropology and Humanism, 37(2), 134-145.

Sarsaneda del Cid, J. (2009). Ni Ngóbe Tó Blitde Ño: Cómo Hablan Los Ngóbe. Panama: Acción Cultural Ngóbe.

Simard, S. W. (2009). The foundational role of mycorrhizal networks in self-organization of interior Douglas-fir forests. Forest Ecology and Management, 258(S), S95-S107.

Sperber, D., \& Hirschfeld, L. A. (2004). The cognitive foundations of cultural stability and diversity. Trends in cognitive sciences, 8(1), 40-46. 
1547

1548

1549

1550

1551

1552

1553

1554

1555

1556

1557

1558

1559

1560

1561

1562

1563

1564

1565

1566

1567

1568

1569

1570

1571

1572

1573

1574

1575

1576

1577

1578

1579

1580

1581

1582

1583

1584

1585

1586

1587

1588
Trewavas, A. (2002). Plant intelligence: Mindless mastery. Nature, 415(6874), 841-841.

Trewavas, A. (2003). Aspects of plant intelligence. Annals of Botany, 92(1), 1-20.

Trewavas, A. (2016). Intelligence, Cognition, and Language of Green Plants. Frontiers in psychology, 7.

Uexküll, J. v. (2010). A foray into the worlds of animals and humans: With a theory of meaning (J. D. O'Neill, Trans. Vol. 12): U of Minnesota Press.

Unsworth, S. J., Levin, W., Bang, M., Washinawatok, K., Waxman, S. R., \& Medin, D. L. (2012). Cultural Differences in Childrens Ecological Reasoning and Psychological Closeness to Nature: Evidence from Menominee and European American Children. Journal of Cognition and Culture, 12(1-2), 17-29.

Viveiros de Castro, E. (1998). Cosmological deixis and Amerindian perspectivism. Journal of the Royal Anthropological Institute, 4(3), 469-488.

von Wiesner, J. (1878). Die Heliotropischen Erscheinungen im Pflanzenreiche: Eine Physiologische Monographie. . [Secondary source, cited from Whippo \& Hangarter, 2006]. Kaiserlich-ko" niglichen Hof- und Staatsdruckerei.

Waldstein, A., \& Adams, C. (2006). The interface between medical anthropology and medical ethnobiology. Journal of the Royal Anthropological Institute, 12(s1), S95-S118.

Waxman, S. R., \& Medin, D. L. (2007). Experience and cultural models matter: Placing firm limits on childhood anthropocentrism. Human Development, 50(1), 23-30.

Weaver, B. (2013). Equivalence of Linear-by-Linear Chi-Square and the ' $\mathrm{N}-1$ ' chi square, 2015, from sites.google.com/a/lakeheadu.ca/bweaver/Home/statistics

Wellman, H. M. (2010). Developing a theory of mind The Blackwell handbook of cognitive development (pp. 258-284).

Wellman, H. M., \& Gelman, S. A. (1992). Cognitive development: Foundational theories of core domains. Annual review of psychology, 43(1), 337-375.

Wellman, H. M., \& Johnson, C. N. (2008). Developing dualism: From intuitive understanding to transcendental ideas. In A. Antonietti, A. Corradina \& E. Lowe (Eds.), Psycho-physical dualism today: An interdisciplinary approach (pp. 3-36). Lanham, MD: Lexington Books.

Wertz, A. E., \& Wynn, K. (2014a). Selective social learning of plant edibility in 6-and 18-monthold infants. Psychological science, 0956797613516145.

Wertz, A. E., \& Wynn, K. (2014b). Thyme to touch: Infants possess strategies that protect them from dangers posed by plants. Cognition, 130(1), 44-49.

Whippo, C. W., \& Hangarter, R. P. (2006). Phototropism: bending towards enlightenment. The Plant Cell Online, 18(5), 1110-1119.

Wilkinson, D. M. (1998). The evolutionary ecology of mycorrhizal networks. Oikos, 82(2), 407-410.

Woodward, A. L. (2013). Infant foundations of intentional understanding. In M. R. Banaji \& S. A. Gelman (Eds.), Navigating the social world: what infants, children, and other species tell us (pp. 75-80): Oxford University Press.

Young, P. D. (1975). Guaymi nativism: its rise and demise. Paper presented at the XLI International Congress of Americanists.

Young, P. D. (1986). Ngawbere numeral classifiers. Paper presented at the Second Annual Meeting of the Pacific Linguistics Conference, Eugene, Oregon. 